\title{
Inverse estimation of source parameters of oceanic radioactivity dispersion models associated with the Fukushima accident
}

\author{
Y. Miyazawa, Y. Masumoto, S. M. Varlamov, T. Miyama, M. Takigawa, M. Honda, and T. Saino \\ Research Institute for Global Change, Japan Agency for Marine-Earth Science and Technology, Yokohama, Kanagawa, Japan \\ Correspondence to: Y. Miyazawa (miyazawa@jamstec.go.jp)
}

Received: 3 September 2012 - Published in Biogeosciences Discuss.: 11 October 2012

Revised: 8 January 2013 - Accepted: 4 March 2013 - Published: 9 April 2013

\begin{abstract}
With combined use of the ocean-atmosphere simulation models and field observation data, we evaluate the parameters associated with the total caesium-137 amounts of the direct release into the ocean and atmospheric deposition over the western North Pacific caused by the accident of Fukushima Daiichi nuclear power plant (FNPP) that occurred in March 2011. The Green's function approach is adopted for the estimation of two parameters determining the total emission amounts for the period from 12 March to 6 May 2011. It is confirmed that the validity of the estimation depends on the simulation skill near FNPP. The total amount of the direct release is estimated as 5.5$5.9 \times 10^{15} \mathrm{~Bq}$, while that of the atmospheric deposition is estimated as $5.5-9.7 \times 10^{15} \mathrm{~Bq}$, which indicates broader range of the estimate than that of the direct release owing to uncertainty of the dispersion widely spread over the western North Pacific.
\end{abstract}

\section{Introduction}

Radionuclides associated with the accident of Fukushima Daiichi nuclear power plant (FNPP) that occurred in March 2011 seriously contaminated the ocean around FNPP as reported by the Nuclear Emergency Response Headquarters (NERH, 2011). There exist two major sources of the ocean contamination (NERH, 2011): direct release from FNPP into the ocean (Kawamura et al., 2011; Tsumune et al., 2012; Bailly du Bois et al., 2011; Masumoto et al., 2012; Miyazawa et al., 2012) and atmospheric deposition (Takemura et al., 2011; Kawamura et al. 2011; Morino et al., 2011; Honda et al., 2012; Stohl et al., 2012; Aoyama et al., 2012b, 2013). Other sources, including indirect release from groundwater, river discharge water, or coastal sediment, introduce the nuclides into the ocean over a long time period (Buesseler et al., 2011; Oura and Ebihara, 2012). The two major sources, however, dominantly drove the oceanic dispersion during the initial period from March to May 2011 and basically determined the total amount of the radionuclides' emission into the ocean (Kawamura et al., 2011; Tsumune et al., 2012; Aoyama et al., 2012a).

Kawamura et al. (2011) evaluated $4 \times 10^{15} \mathrm{~Bq}(4 \mathrm{PBq})$ of the total amount of caesium-137 $\left({ }^{137} \mathrm{Cs}\right)$ directly released into the ocean for the period from 21 March to 30 April 2011 using their numerical ocean model and the observations in front of FNPP. Tsumune et al. (2012) also evaluated $3.5 \pm 0.7 \mathrm{PBq}$ of the ${ }^{137} \mathrm{Cs}$ amount for the period from 26 March to 30 May 2011 based on a similar method. Several numerical simulations of the ${ }^{137} \mathrm{Cs}$ dispersion show some similarity and difference among them (Masumoto et al., 2012). It is useful and necessary to evaluate the total amount of direct release using different models based on different methods for better understanding of uncertainty involved in this kind of estimations.

The total amount of the atmospheric deposition over the ocean was also evaluated using numerical model simulations with combined use of the field observation data by several groups, e.g., $5 \mathrm{PBq}$ for the period from $12 \mathrm{March}$ to 30 April 2011 (Kawamura et al., 2011). The atmospheric deposition effectively transported the radionuclides over the North Pacific during the initial period (Honda et al., 2012; Aoyama et al., 2013). Using an output of the atmospheric dispersion model, our previous study (Honda et al., 2012) suggested that the anomalous ${ }^{137} \mathrm{Cs}$ concentration measured at a point far from FNPP $\left(47^{\circ} \mathrm{N}, 160^{\circ} \mathrm{E}\right)$ on 21 April 2011, just after one month of the Fukushima accident, was actually caused by 
the atmospheric deposition. We also suggested that the total deposition amount of our previous model $(0.18 \mathrm{PBq}$ within March 2011) was much lower than the other estimate of $5 \mathrm{PBq}$ (Kawamura et al., 2011) even though both the models used the same source information (Chino et al., 2011). The difference could come from the large uncertainty of the fallout to the parameterizations of the wet and dry deposition processes (Stohl et al., 2012).

In this study we estimate the total ${ }^{137} \mathrm{Cs}$ amounts of the direct release and atmospheric deposition on the sea originating from FNPP during the initial period from 12 March to 6 May 2011 by using the outputs from numerical oceanatmosphere models and all available field observation data. For this we adopt the Green's function approach, which is a simple but quite effective method for the estimation of unknown model parameters (Menemenlis et al., 2005). The previous estimates of the total amount of the direct release were estimated based on the comparison of the simulated and observed concentrations in front of FNPP (Kawamura et al., 2011; Tsumune et al., 2012), but our actual estimation is obtained by utilizing all available observation data acquired during the target period over the western North Pacific.

This paper is organized as follows. Section 2 provides a description on the simulation models and observation data used in this study. Section 3 describes first-guess simulation results as basis of the parameters estimation. The Green's function approach for the parameters estimation is described in Sect. 4. The estimation result and its implications on the oceanic dispersion of the radionuclides associated with the Fukushima accident are discussed in Sect. 5, and then briefly summarized in Sect. 6.

\section{Simulations and data}

\subsection{Simulation models}

We use a transport model of ${ }^{137} \mathrm{Cs}$ for dispersion simulations (Miyazawa et al., 2012):

$$
\frac{\partial C}{\partial t}=\mathrm{ADV}(U, C)+\operatorname{DIF}(U, C)-\lambda C+\delta\left(x_{0}, y_{0}, z_{0}\right) D_{\mathrm{o}}(t),
$$

where $C$ is three-dimensional concentration of ${ }^{137} \mathrm{Cs}$. The first and second terms of the right-hand side denote advection by three-dimensional ocean current $U$ and harmonic diffusion, respectively. Horizontal diffusion coefficients due to sub-grid scale phenomena are evaluated by the formula of Smagorinsky (1963) using the ocean current. Vertical diffusion coefficients are calculated by a parameterization based on a turbulence closure model (Mellor and Blumberg, 2004). A constant value $\lambda=\ln (2) / T_{\text {half }}\left(T_{\text {half }}=30.1 \mathrm{yr}\right)$ represents the half-life time decay effect of the radionuclide for ${ }^{137} \mathrm{Cs}$. A first-guess surface flux of ${ }^{137} \mathrm{Cs}$ is provided from atmospheric deposition $D_{\mathrm{a}}^{\mathrm{f}}(x, y, t)$ simulated by an atmospheric dispersion model (Honda et al., 2012),

$\left.K_{\mathrm{v}} \frac{\partial C}{\partial z}\right|_{z=\eta}=D_{\mathrm{a}}^{\mathrm{f}}(x, y, t)$,

where $K_{\mathrm{v}}$ is the vertical diffusion coefficient, and $z=\eta$ is sea surface level. The information of ${ }^{137} \mathrm{Cs}$ direct release from FNPP is included by a flux term indicated by the fourth term of the right-hand side. $\delta\left(x_{0}, y_{0}, z_{0}\right)$ is 1 only at a surface source grid in front of FNPP and is 0 at all other grids. $D_{\mathrm{o}}(t)$ denotes a function of ${ }^{137} \mathrm{Cs}$ direct release flux from FNPP. We use grid coordinates and ocean currents provided from two different ocean general circulation models - JCOPE2 (Miyazawa et al., 2009) and JCOPE-T (Guo et al., 2010; Miyazawa et al., 2012) - to examine sensitivity of simulation results on possible model biases. Note that Eq. (1) does not involve the sediment and biological processes (Masumoto et al., 2012), although their roles are non-negligible, especially for the whole ${ }^{137} \mathrm{Cs}$ dispersion process on a long time scale.

A basin-scale model JCOPE2 (Miyazawa et al., 2009) developed based on Princeton Ocean Model with generalized coordinate of sigma (Mellor et al., 2002) provides daily mean ocean current data covering the western North Pacific $\left(10.5-62^{\circ} \mathrm{N}, 108-180^{\circ} \mathrm{E}\right)$ with a horizontal resolution of $1 / 12^{\circ}$. The main objective of JCOPE2 is a description of the observed oceanic variability associated with the Kuroshio, Kuroshio-Extension, Oyashio, and mesoscale eddies around Japan. The JCOPE2 model thus assimilates the remote-sensing data of altimetry and surface temperature and in situ data of temperature and salinity profiles. Surface momentum and heat fluxes are calculated by using the bulk formulae (Kagimoto et al., 2008) with atmospheric variables obtained from the National Centers for Environmental Prediction/National Center for Atmospheric Research (NCEP/NCAR) reanalysis (Kalnay et al., 1996). Sea surface salinity flux is represented by a relaxation term to monthly climatological data of sea surface salinity (Conkright et al., 2002).

The JCOPE-T-1 model (Guo et al., 2010; Miyazawa et al., 2012) is a downscaled version of JCOPE2 and provides hourly data of ocean current covering the Japan coastal ocean $\left(28-44^{\circ} \mathrm{N}, 125-148^{\circ} \mathrm{E}\right)$ with horizontal resolution of $1 / 36^{\circ}$. The lateral boundary condition is given by the JCOPE2 model. The observed features of mesoscale phenomena are represented by nudging of temperature and salinity toward the JCOPE2 data. The most significant difference between JCOPE2 and JCOPE-T-1 is that only the latter model includes explicit tidal forcing. Tidal forcing composed of 16 constituents is included in JCOPE-T-1 by additions of equivalent surface pressure gradient. The tidal velocity and sea level anomaly provided from a tide model (Matsumoto et al., 2000) are also specified at lateral boundaries. Another feature of JCOPE-T- 1 that is different from JCOPE2 is the inclusion of lateral fresh water inputs from 35 major river mouths, including the Kitakami and Abukuma rivers near 
FNPP (Fig. 1b). Surface fluxes of momentum, heat, and fresh water are calculated using sophisticated algorithms (Li et al., 2010) with hourly data of atmospheric variables obtained from the Japan Meteorological Agency nonhydrostatic Meso Scale Model (JMA MSM; Saito et al., 2007), which has much higher horizontal resolution of $5 \mathrm{~km}$ as compared to a few hundred $\mathrm{km}$ resolution of the NCEP/NCAR reanalysis data used for the JCOPE2 model. The JCOPE-T-1 current was also used for a dispersion simulation described in our previous studies (Masumoto et al., 2012; Miyazawa et al., 2012). The updated version of JCOPE-T-1: JCOPE-T-2, is slightly modified by changing the time scale of the nudging toward the JCOPE2 temperature and salinity from 20 days over the whole region to 5 days in the open ocean with water depth larger than $200 \mathrm{~m}$. In addition, the nudging of the present model is removed in the shallow region with water depth smaller than $200 \mathrm{~m}$. The modification of the nudging time scale actually improved the biases of intensification of Oyashio and relevant southward deviation of the latitudinal position of Kuroshio Extension (e.g., see Fig. 3 in Masumoto et al., 2012) found in the previous version, JCOPE-T-1.

Distributions of surface currents averaged for the simulation period (Fig. 1) indicate that the southward current associated with the Oyashio intrusion is represented in open ocean with bottom depth larger than $200 \mathrm{~m}$ by both JCOPE2 (Fig. 1a) and JCOPE-T-2 (Fig. 1b). An anticyclonic eddy near the coast south of $37^{\circ} \mathrm{N}$ is also represented by both models. The northeastward flow of the Kuroshio Extension is reproduced around $36.8^{\circ} \mathrm{N}$ in JCOPE2 as reported in the Quick Bulletin of oceanographic conditions provided from Japan Coast Guard, but it is not shown around this latitude in JCOPE-T-2, indicating a remaining southward bias of the Kuroshio Extension front position in this version of JCOPE-T-2. River discharges flows from two major rivers near FNPP (the Kitakami and Abukuma rivers) are represented in JCOPE-T-2.

Atmospheric deposition of ${ }^{137} \mathrm{Cs}$ is estimated by a oneway nested regional air quality forecasting (AQF) system described by Honda et al. (2012). The model domain covers the western Pacific with a horizontal resolution of $10 \mathrm{~km}$. Source information of ${ }^{137} \mathrm{Cs}$ is given by a scenario of ${ }^{137} \mathrm{Cs}$ emission from the FNPP created by combined use of the SPEEDI reverse method (Chino et al., 2011) and data in Tokyo Electric Power Corporation (TEPCO) reports (Honda et al., 2012). The system is driven by meteorological data from the NCEP operational global analysis data set. Wet and dry deposition schemes used in AQF are based on Maryon et al. (1996). Three significant peaks of atmospheric deposition integrated over the western North Pacific $\left(10.5-62^{\circ} \mathrm{N}, 108-180^{\circ} \mathrm{E}\right)$ are depicted in the time sequence (Fig. 2). The total amount of the atmospheric deposition in the western North Pacific for the period from 11 March to 6 May 2011 is $0.3 \mathrm{PBq}$. Horizontal distribution of the accumulated deposition is depicted in the Fig. 3 from Honda et al. (2012). (a)

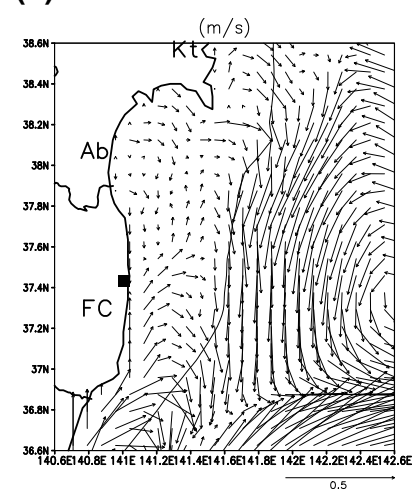

(b)

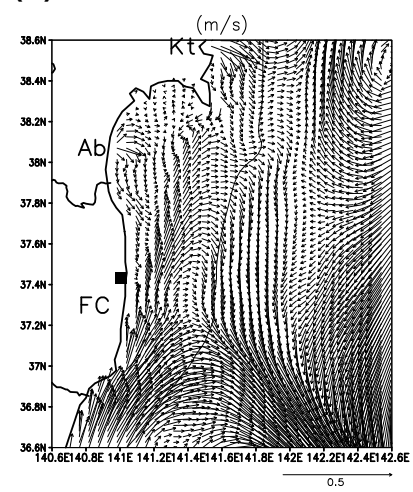

Fig. 1. Simulated ocean current at $1 \mathrm{~m}$ depth averaged for the period from 21 March 2011 to 6 May 2011. A thick line denotes an isodepth contour showing $200 \mathrm{~m}$ depth. A closed square indicates the position of FNPP. Abbreviations "Ab", "Kt", and "FC" indicate the river month positions of the Abukuma and Kitakami rivers, and Fukushima coast, respectively. (a) JCOPE2 (b) JCOPE-T-2

\subsection{Observation data}

To adjust model parameters associated with the emission amounts, we utilize two kinds of observation data: (1) data of urgent monitoring by TEPCO and the Ministry of Education, Culture, Sports, Science and Technology (MEXT) with relatively large values of measurement uncertainty and detection limit, and (2) more precise data obtained by research cruises of RVs Tansei, Mirai, and volunteer ships managed by NYK LINE (Table 1 for detail). Spatial sampling density is higher in the former types of data measured near FNPP than in the latter types of data measured far from it (Fig. 3). Table 1 summarizes the information of the observation data used in this study. Note that data showing no detection of ${ }^{137} \mathrm{Cs}$ are excluded from our analysis.

\section{First-guess simulations}

A first guess of the direct release flux term $D_{\mathrm{o}}^{\mathrm{f}}(t)$ is evaluated using the daily observation data of ${ }^{137} \mathrm{Cs}$ near the FNPP as the following:

$D_{\mathrm{o}}^{\mathrm{f}}(t)=\frac{\left(C_{\text {grid }} \cdot C_{\mathrm{obs}}-C\left(x_{0}, y_{0}, z_{0}, t\right)\right)}{T_{\mathrm{s}}}$,

where $C_{\mathrm{obs}}$ and $C\left(x_{0}, y_{0}, z_{0}, t\right)$ denote an average of two observed concentrations in front of FNPP (the 5th-6th and south discharge canal waters; Tsumune et al., 2012) and simulated concentration at the source grid, respectively. Magnitude of the flux is determined by a relaxation time scale $T_{\mathrm{s}}$, which is assumed to be $36 \mathrm{~h}$ in this study. $C_{\text {grid }}$ denotes a constant for adjustment of a grid size effect, which equals $1 / 9$ in the simulation using the JCOPE2 grid $\left(1 / 12^{\circ}\right)$, but equals 1 in the JCOPE-T- 1 and -2 simulations with the $1 / 36^{\circ}$ 
Table 1. Information of ${ }^{137} \mathrm{Cs}$ observation data obtained for the period from 21 March to 6 May 2011. (Total amount: 417 samples.)

\begin{tabular}{|c|c|c|c|c|}
\hline Name & $\begin{array}{l}\text { Number } \\
\text { of } \\
\text { points }\end{array}$ & $\begin{array}{l}\text { Error } \\
\left(\mathrm{BqL}^{-1}\right)\end{array}$ & $\begin{array}{l}\text { Detection } \\
\text { limit } \\
\left(\mathrm{BqL}^{-1}\right)\end{array}$ & Reference \\
\hline TEPCO & 18 & 5 & 15 & $\begin{array}{l}\text { TEPCO (2011), } \\
\text { Buesseler et al. (2011) }\end{array}$ \\
\hline MEXT & 12 & 3.3 & 10 & $\begin{array}{l}\text { MEXT (2011), } \\
\text { Buesseler et al. (2011) }\end{array}$ \\
\hline MIRAI* & 29 & $0.005-0.001$ & 0.002 & Honda et al. (2012) \\
\hline TANSEI ${ }^{*}, * * *$ & 21 & 0.09 & 0.12 & Aoyama et al. (2013) \\
\hline $\mathrm{NYK}^{* *}, * * *$ & 72 & $0.06-0.0002$ & 0.0004 & Aoyama et al. (2013) \\
\hline Oarai & 5 & 3 & 9 & Oarai Town $* * * *$ \\
\hline
\end{tabular}

* The MIRAI and TANSEI data were sampled by the research cruises.

** The NYK data were sampled through volunteer ships cruises managed by Nippon Yusen Kabushiki Kaisha (NYK LINE).

*** Data are available at: http://www.mri-jma.go.jp/Topics/hotyouhi/houtyouhi_sea_en.html.

**** Data are available at: http://www.town.oarai.lg.jp/ koushitsu/housyasenn/info_g_3_1351.html (in Japanese).

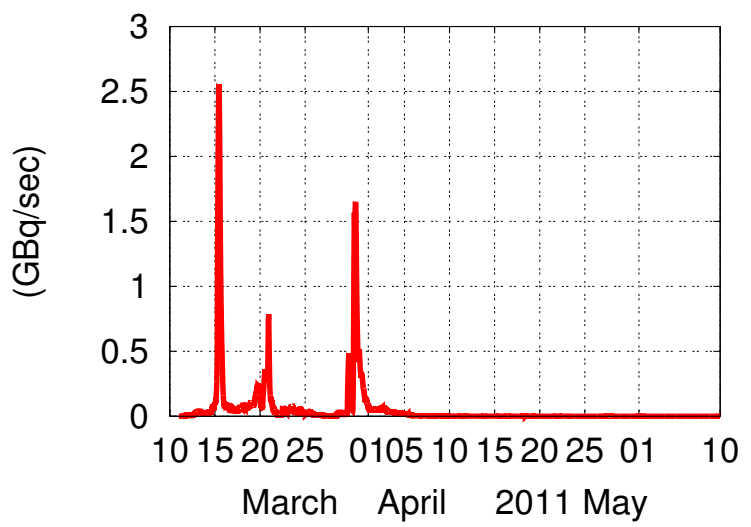

Fig. 2. Time sequences of the simulated atmospheric deposition flux (in $\mathrm{GBq} \mathrm{s}^{-1}$ ) integrated over the western North Pacific, $10.5-62^{\circ} \mathrm{N}$ and $108-180^{\circ} \mathrm{E}$.

grid to allow similar levels of total emission amount between the JCOPE2 and JCOPE-T-1 and -2 simulations. To estimate the first-guess flux of direct release, we perform two base simulations using the JCOPE-T-1 and JCOPE2 current data without the atmospheric deposition. Note that the JCOPE$\mathrm{T}-2$ current data were calculated after the derivation of the JCOPE-T-1 flux, which may not be much different from the flux based on the JCOPE-T- 2 current data. We thus decide to use the JCOPE-T-1 flux for both the JCOPE-T-1 and JCOPE$\mathrm{T}-2$ cases.

Time sequences of calculated direct release fluxes (Fig. 4) show two peaks of significant emission during the period from the end of March to the beginning of April. Total amounts of estimated direct release for the period from 21 March to 6 May are 1.9 PBq for JCOPE-T-1 and 1.6 PBq for JCOPE2. A slightly larger amount evaluated in the JCOPET-1 flux as compared to the JCOPE2 flux suggests effective
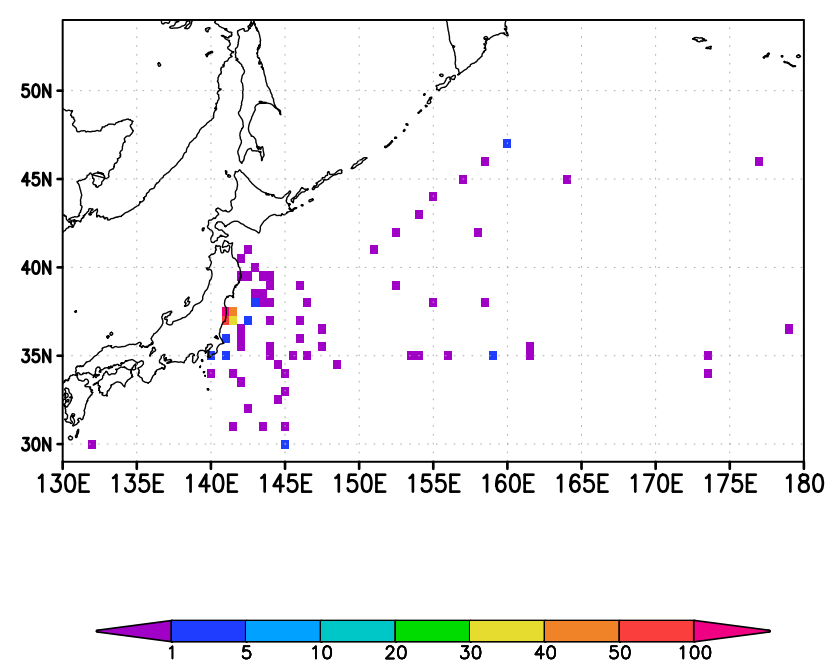

Fig. 3. Numbers of the caesium-137 $\left({ }^{137} \mathrm{Cs}\right)$ measurements within $1^{\circ} \times 1^{\circ}$ grids sampled during the period from 21 March to 6 May 2011 .

${ }^{137} \mathrm{Cs}$ transport from the source grid to the surrounding region in the JCOPE-T-1 simulation due to its more energetic ocean current variation around FNPP (not shown).

We use another type of the flux, $D_{\mathrm{o}}^{\mathrm{f}}(t)$, proposed by a research group of Japanese Central Research Institute of Electric Power Industry (CRIEPI), whose time sequence is also shown in Fig. 4. We call this type of flux the CRIEPI flux with total release amount of $3.5 \mathrm{PBq}$ (Tsumune et al., 2012). Note that the CRIEPI (JCOPE-T-1 and JCOPE2) flux assumes the direct release starting from 26 (21) March 2011 (see Fig. 4). However, the release amount for the period from 21 to 25 March 2011 estimated in the JCOPE-T- 1 and JCOPE2 fluxes is not so large as compared to that for the later period. 


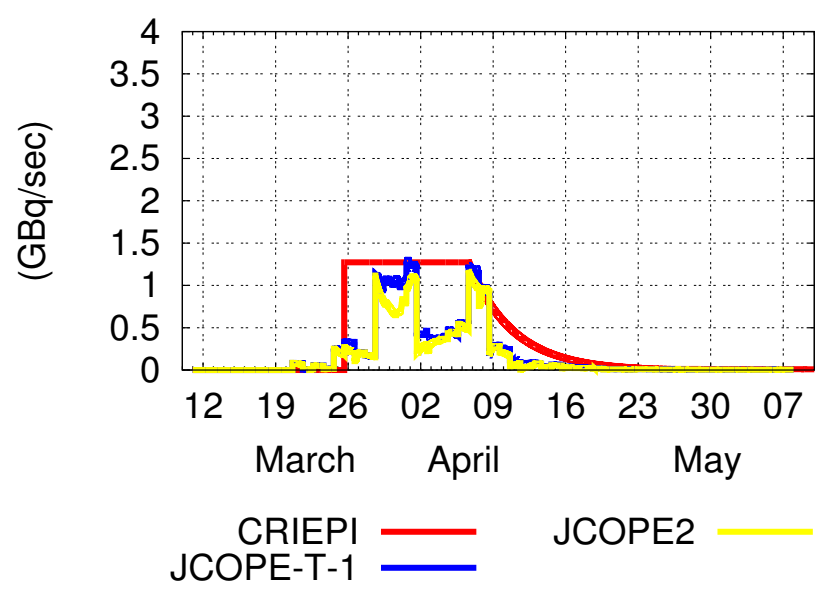

Fig. 4. Time sequences of the first-guess direct release fluxes.

Five cases of the first-guess simulations used for the inverse estimation are summarized in Table 2. Ocean current data include JCOPE-T-1 with horizontal resolution of $1 / 36^{\circ}$, JCOPE-T-2 with $1 / 36^{\circ}$, and JCOPE2 with $1 / 12^{\circ}$. Three types of the direct release flux - JCOPE-T-1, JCOPE2, and CRIEPI - are adopted. All first-guess simulations specify zero atmospheric deposition flux. To compare level of agreement between the simulations and observation, we calculate values of a cost function

$C=\left(\boldsymbol{y}-\vec{x}^{\mathrm{f}}-\boldsymbol{x}^{\mathrm{b}}\right)^{t} \mathbf{R}^{-1}\left(\boldsymbol{y}-\vec{x}^{\mathrm{f}}-\vec{x}^{\mathrm{b}}\right)$,

where $\quad \overrightarrow{x^{\mathrm{f}}}=\left(x_{1}^{\mathrm{f}}, \ldots x_{N}^{\mathrm{f}}\right)^{t} \quad$ and $\quad \vec{y}=\left(y_{1}^{\mathrm{o}}, \ldots y_{N}^{\mathrm{o}}\right)^{t}$ denote $N$ number concentration values of the simulation and observation, respectively; $\overrightarrow{x^{\mathrm{b}}}=$ $\left(0.001 \mathrm{~Bq} \mathrm{~L}^{-1}, \ldots, 0.001 \mathrm{~Bq} \mathrm{~L}^{-1}\right)^{t}$ are the background ${ }^{137} \mathrm{Cs}$ concentration (Aoyama et al., 2013); $\mathbf{R}$ denotes an $N \times N$ observation error covariance matrix whose diagonal components are specified from the measurement errors described in Table 1. Non-diagonal components of $\mathbf{R}$ are all zeros.

The JCOPE2 simulation shows the largest cost value that is significantly larger than all other simulations of the finer grid, suggesting that a coarse resolution of the model $\left(1 / 12^{\circ}\right)$ is insufficient to represent observed ${ }^{137} \mathrm{Cs}$ variations. A larger total amount of the direct release flux represent by the CRIEPI flux results in smaller values of the cost function than those evaluated using the JCOPE-T-1 fluxes with the smaller total amount, indicating that the total direct release amount may be larger than 1.9 PBq of the JCOPE-T-1 flux total amount.

Figure 5 shows a sequence of weekly mean concentration calculated by the first-guess JCOPE-T-2-C simulation that has a best fitting to the observation as a result of the parameters estimation (Table 3) described in Sect. 4. The horizontal dispersion process inside of the shelf is basically governed by the wind-forced current (Tsumune et al., 2012; Miyazawa et al., 2012). The dispersion is limited near the coast within March 2011 (Fig. 5a and b). Then the dispersion elongates toward the northeastward direction in April (Fig. 5c-f). A change of dominant wind direction from northerly and/or easterly to southerly and/or westerly accounts for that of the dominant dispersion direction (Miyazawa et al., 2012). Figure 5 also indicates that the concentration measured along $141.4^{\circ} \mathrm{E}$ is basically underestimated by the first-guess simulation. The atmospheric deposition and/or underestimation of the direct release may be responsible for the disagreement between the first-guess simulation and observation.

\section{Inverse estimation of source parameters}

The first-guess simulations suggest that the absolute levels of the simulated ${ }^{137} \mathrm{Cs}$ concentration could be adjusted based on comparison of the simulated and observed concentration values. We estimate two simple scaling factors $\left(S_{\mathrm{a}}\right.$, hereafter the atmospheric parameter, and $S_{\mathrm{o}}$, hereafter the ocean parameter) for the adjustment of the atmospheric deposition

$\left.K_{\mathrm{v}} \frac{\partial C}{\partial z}\right|_{z=\eta}=\left(O_{\mathrm{a}}+S_{\mathrm{a}}\right) D_{\mathrm{a}}^{\mathrm{f}}(x, y, t)$,

and direct release fluxes

$D_{\mathrm{o}}(t)=\left(O_{\mathrm{o}}+S_{\mathrm{o}}\right) D_{\mathrm{o}}^{\mathrm{f}}(t)$

where $O_{\mathrm{a}}=0$ and $O_{\mathrm{o}}=1$ are original values of the atmospheric and ocean parameters, respectively.

The Green's function approach (Menemenlis et al., 2005) is effective for the parameters estimation since it enables us to take account of error covariance among different parameters. $N$ numbers of observation values $\vec{y}$ are approximated using the Green's function: $\vec{y}=G \overrightarrow{\Delta \eta}+\overrightarrow{x^{\mathrm{f}}}+\overrightarrow{x^{\mathrm{b}}}+\vec{\varepsilon}$, where $\overrightarrow{\Delta \eta}=\left(\begin{array}{c}S_{\mathrm{a}} \\ S_{\mathrm{o}}\end{array}\right)$ and $\vec{\varepsilon}$ denote the errors of the estimation: $\vec{\varepsilon}=\left(\varepsilon_{1}, \ldots, \varepsilon_{N}\right)^{t}$. The Green's function

$G=\left(\begin{array}{cc}G_{11} & G_{12} \\ \cdot & \cdot \\ \cdot & \cdot \\ G_{N 1} & G_{N 2}\end{array}\right)$

is calculated from results of parameters sensitivity experiments as follows:

$G_{n 1}=\left(x_{n}^{\mathrm{a}}-x_{n}^{\mathrm{f}}\right) / S_{\mathrm{a}}^{1} \quad$ and

$G_{n 2}=\left(x_{n}^{\mathrm{o}}-x_{n}^{\mathrm{f}}\right) / S_{\mathrm{o}}^{1}(n=1, \ldots, N)$,

where $x_{n}^{\mathrm{a}}$ and $x_{n}^{\mathrm{o}}$ are ${ }^{137} \mathrm{Cs}$ concentrations corresponding to the $\mathrm{n}$-th observation calculated by the sensitivity experiments for the atmospheric deposition with perturbed parameter of $S_{\mathrm{a}}^{1}$ and direct release with $S_{\mathrm{o}}^{1}$, respectively. Optimized parameters to minimize a cost function $\vec{\varepsilon}^{t} \mathbf{R}^{-1} \vec{\varepsilon}$ are obtained as 
Table 2. Description of first-guess simulations.

\begin{tabular}{lllrr}
\hline & $\begin{array}{l}\text { Current } \\
\text { data }\end{array}$ & $\begin{array}{l}\text { Direct } \\
\text { release } \\
\text { flux }\end{array}$ & $\begin{array}{r}\text { Total amount } \\
\text { of direct } \\
\text { release (PBq) }\end{array}$ & Cost* \\
\hline JCOPE-T-1 & JCOPE-T-1 & JCOPE-T-1 & 1.9 & 619400 \\
JCOPE-T-1-C & JCOPE-T-1 & CRIEPI & 3.5 & 350606 \\
JCOPE-T-2 & JCOPE-T-2 & JCOPE-T-1 & 1.9 & 630695 \\
JCOPE-T-2-C & JCOPE-T-2 & CRIEPI & 3.5 & 379398 \\
JCOPE2 & JCOPE2 & JCOPE2 & 1.6 & $1015443(1020916)^{* *}$ \\
\hline
\end{tabular}

* Cost function values Eq. (4) are calculated using the observation data included in the JCOPE-T model region.

** A number in a parenthesis denotes a cost function values calculated using all observation data included in the JCOPE2 model region.

$$
\overrightarrow{\Delta \eta}^{\mathrm{o}}=\mathbf{P} G^{t} \mathbf{R}^{-1}\left(\boldsymbol{y}-\boldsymbol{x}^{\mathrm{f}}-\boldsymbol{x}^{\mathrm{b}}\right), \mathbf{P}=\left(G^{t} \mathbf{R}^{-1} G\right)^{-1},
$$

where $\mathbf{R}$ and $\mathbf{P}$ represent an error covariance matrix of the observations and parameters, respectively. We assume that the observation error covariance matrix $\mathbf{R}$ is diagonal with the variance calculated from measurement errors mentioned in Sect. 2.2. Since the model linearly responds to the perturbations of the flux parameters shown in Eqs. (5) and (6), we expect that the Green's function approach works well for the parameters optimization (Menemenlis et al., 2005).

We conduct two sensitivity experiments perturbing the atmospheric $\left(S_{\mathrm{a}}=2\right)$ and ocean $\left(S_{\mathrm{o}}=1\right)$ parameters for each first-guess simulation. Note that we exclude observations obtained from two points in front of FNPP (the 5th-6th and south discharge canal waters) from Eqs. (4) and (9) because the horizontal grids of our models $-1 / 36^{\circ}$ and $1 / 12^{\circ}$ - may be too coarse to represent the ${ }^{137} \mathrm{Cs}$ variation in front of FNPP. The optimization results based on the five cases of the firstguess simulations are summarized in Table 3 . The cost function value expected in the case with the optimized parameters (the expected cost) is calculated as

$$
C_{G}=\left(\boldsymbol{y}-\vec{x}^{\mathrm{f}}-G \overrightarrow{\Delta \eta^{\mathrm{o}}}-\boldsymbol{x}^{\mathrm{b}}\right)^{t} \mathbf{R}^{-1}\left(\boldsymbol{y}-\vec{x}^{\mathrm{f}}-G \overrightarrow{\Delta \eta^{\mathrm{o}}}-\vec{x}^{\mathrm{b}}\right)
$$

The Green's function approach allows evaluation of optimal values for each single parameter separately, while it also allows evaluation of optimal multiple parameters simultaneously (Menemenlis et al., 2005). Optimizations of multiple parameters for the direct release and atmospheric deposition (see second and third columns of Table 3) generally exhibit more reduction of the expected cost values than optimizations for either single parameter (see fourth and fifth columns of Table 3). The errors of the parameters estimation are represented in the diagonal components of the error covariance matrix P (Menemenlis et al., 2005; also see Eq. 9). The orders of the errors are $\mathrm{O}\left(10^{-3}\right)$ and $\mathrm{O}\left(10^{-2}\right)$ PBqs for the direct release and atmospheric deposition, respectively, and are much smaller than the differences of $\mathrm{O}\left(10^{-1}\right)-\mathrm{O}(1) \mathrm{PBq}$ among the estimates for different ocean currents and firstguess direct release fluxes, as shown in Table 3.

\section{Discussion}

The optimization for the multiple parameters using the coarse grid model JCOPE2 fails in the estimation of the realistic amount of the atmospheric deposition, which is evaluated as a negative value (Table 3). To examine the failed estimation process in detail, we calculate contribution rates $C_{n m}^{\mathrm{r}}$ (in \%; $m=1,2$ ) of the each measurement for the parameters estimation,

$$
C_{m n}^{\mathrm{r}}=\left[\mathbf{P} G^{T}\right]_{m n}\left[\mathbf{R}^{-1}\left(\vec{y}-\boldsymbol{x}^{f}-\boldsymbol{x}^{\mathrm{b}}\right)\right]_{n} \frac{100}{\left|\left[\overrightarrow{\Delta \eta^{\mathrm{o}}}\right]_{m}\right|},
$$

where $[\cdot]_{m n}$ and $[\cdot]_{n(m)}$ denote components of a matrix and a vector, respectively. The contribution rates $C_{n m}^{r}$ are useful to distinguish contribution of an observation $y_{n}^{\mathrm{o}}$ for the optimized parameter perturbation $\left[\overrightarrow{\Delta \eta^{0}}\right]_{m}$, as suggested by the following equation:

$$
\begin{gathered}
100 \times \frac{\left[\overrightarrow{\Delta \eta^{\mathrm{o}}}\right]_{m}}{\left|\left[\overrightarrow{\Delta \eta^{\mathrm{o}}}\right]_{m}\right|}=\sum_{n=1}^{N}\left[\mathbf{P} G^{T}\right]_{m n}\left[\mathbf{R}^{-1}\left(\vec{y}-\boldsymbol{x}^{\mathrm{f}}-\boldsymbol{x}^{\mathrm{b}}\right)\right]_{n} \\
\frac{100}{\left|\Delta \eta_{m}^{\mathrm{o}}\right|}=\sum_{n=1}^{N} C_{m n}^{\mathrm{r}} .
\end{gathered}
$$

Figure 6 compares the contribution rates of JCOPE-T-2-C (upper panels), which has the smallest cost function value, and JCOPE2 (lower panels), which has the largest cost function value (Table 3). The unrealistic negative perturbation of the atmospheric parameter in the JCOPE2 case is caused by the adjustment to the observations near the coast and one observation around $36^{\circ} \mathrm{N}, 146^{\circ} \mathrm{E}$ (Fig. $6 \mathrm{~A}-2$ ), while almost all observations force positive perturbation of the atmospheric parameter in the JCOPE-T-2-C case (Fig. 6A-1). The negative perturbation of the atmospheric parameter shown near the coast (Fig. 6A-2) seems to be compensated for by the positive perturbation of the ocean parameter there (Fig. 6O2). The worst representation skill of JCOPE2 indicated by the largest cost function value (Table 2) is mainly attributed to the model performance near the coast (not shown). The 


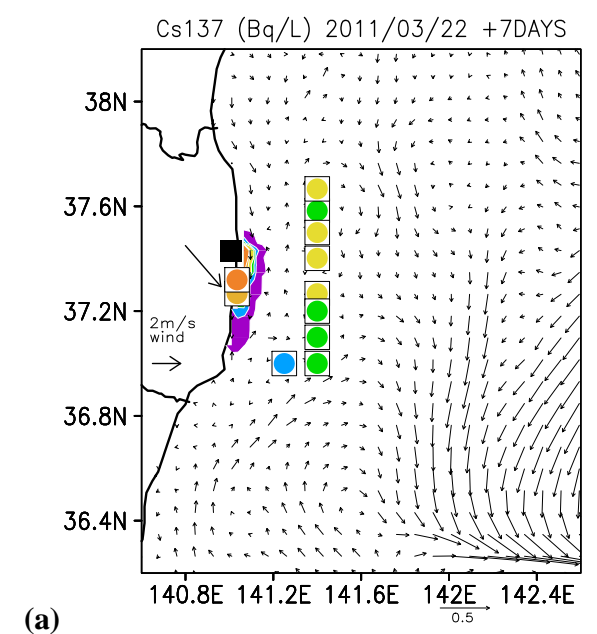

(a)

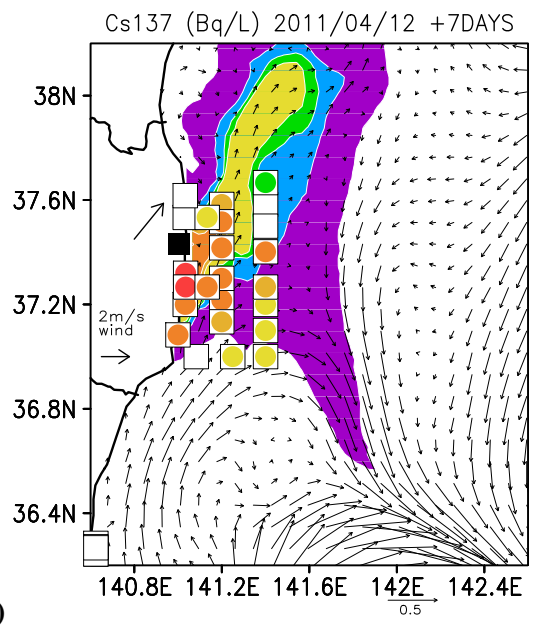

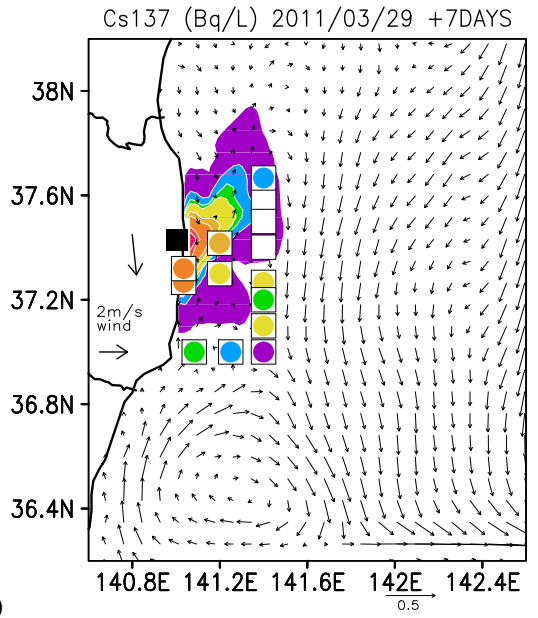

(b)

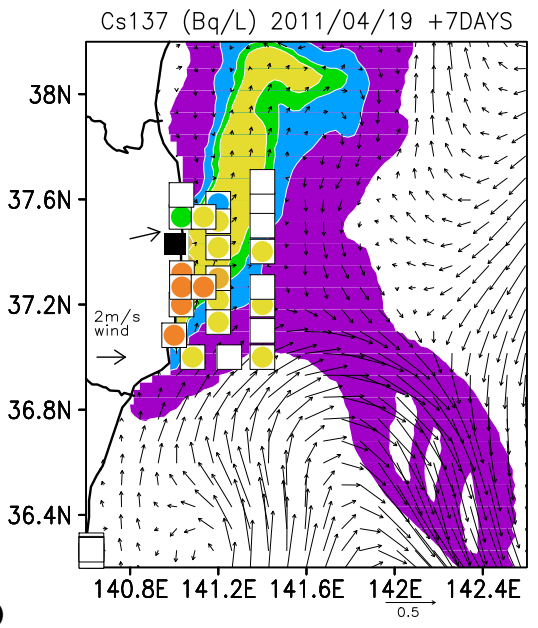

(e)

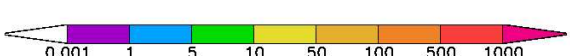

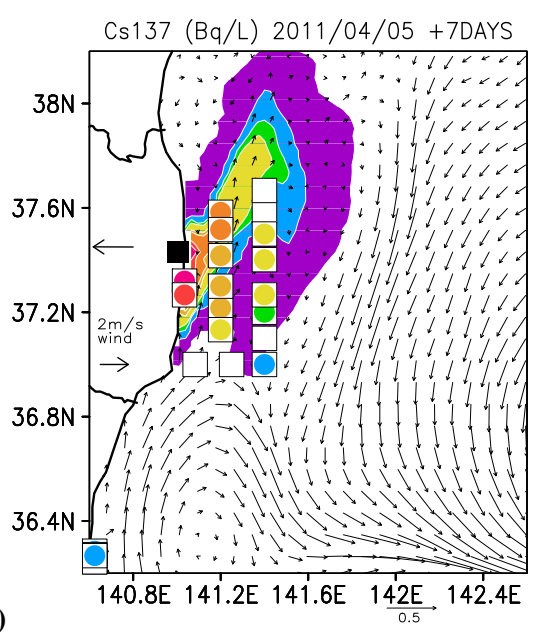

(c)

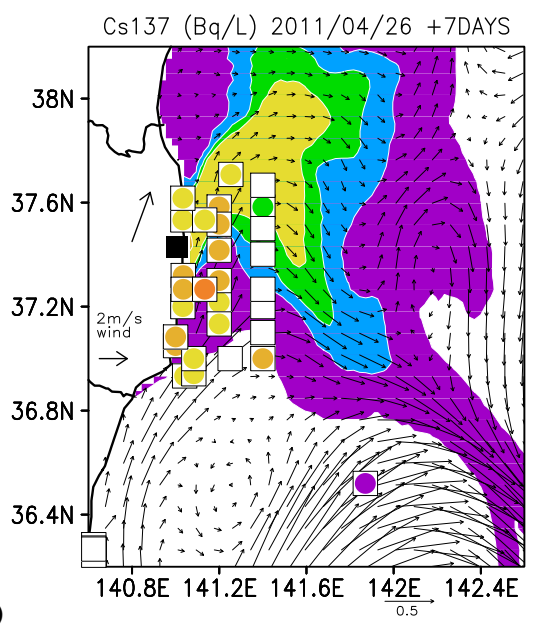

Fig. 5. Time sequences of weekly averaged concentration (in $\mathrm{Bq} \mathrm{L}$ ) at $1 \mathrm{~m}$ depth (shade) of ${ }^{137} \mathrm{Cs}$ around Fukushima simulated by the JCOPET-2-C first-guess simulation. Vectors indicate the weekly averaged current at $1 \mathrm{~m}$ depth used for the simulation. The beginning days of the weekly averages are shown at top of panels. The position of FNPP is denoted by a closed square. Closed circles surrounded by open squares indicate in situ observation points during each averaged period. Colors of the closed circles denote ranges of the concentration. White color means that the concentration was not detected there. A vector shown in left of the FNPP point indicates the weekly averaged wind of JMA MSM on a grid in front of FNPP.

negative perturbation of the atmospheric parameter in the JCOPE2 case could come partly from the worse simulation skill near the coast.

Another part of observation associated with the negative perturbation of the atmospheric parameter around $36^{\circ} \mathrm{N}$, $146^{\circ} \mathrm{E}$ contributes to decreases in the ocean parameter (Fig. 6O-2). Comparison between the concentration maps of JCOPE-T-2-C and JCOPE2 with only the direct release flux in the last week of April 2011 (Fig. 8) indicates that the coarser grid of JCOPE2 results in more diffusive horizontal dispersion as compared to JCOPE-T-2-C with the finer grid. The diffusive dispersion of JCOPE2 facilitates the transport of more amounts of 137CS along the northern edge of the Kuroshio Extension than expected from the observation, re- sulting in the negative perturbations in both of the atmospheric and ocean parameters around $36^{\circ} \mathrm{N}, 146^{\circ} \mathrm{E}$ (Fig. 6O2 and A-2). The concentration map of JCOPE-T-2-C (Fig. 8a) suggests that the concentration caused by the direct release is almost limited in the shelf region, and the observed concentration in open ocean might be caused by the atmospheric deposition at the time of the last week of April 2011. This is also supported by the contribution rates of JCOPE-T-2-C (Fig. 6O-1 and A-1) showing the positive (negative) perturbations of the atmospheric (ocean) parameter in open ocean. The optimized positive perturbation of the ocean parameter in JCOPE-T-2-C is basically determined by the response to the observations near the coast (Fig. 6O-1), which also 
Table 3. Summary of the parameters optimization. Two-digit numbers denote estimated total amounts of ${ }^{137} \mathrm{Cs}$ emission in PBq. Numbers in parentheses denote the expected costs Eq. (10), except for JCOPE-T-2-C-E. Percent numbers present reduced ratios of the expected cost function values as compared to the first-guess cost function values (see Table 2). "Multiple" ("Single") means the parameters in the optimization with both the ocean and atmospheric parameters (either single parameter).

\begin{tabular}{lrrrr}
\hline & $\begin{array}{r}\text { Ocean- } \\
\text { Multiple }\end{array}$ & $\begin{array}{r}\text { Atmosphere- } \\
\text { Multiple }\end{array}$ & $\begin{array}{r}\text { Ocean- } \\
\text { Single }\end{array}$ & $\begin{array}{r}\text { Atmosphere- } \\
\text { Single }\end{array}$ \\
\hline JCOPE-T-1 & $5.6(240984,39 \%)$ & $1.2(240984)$ & $5.6(243821)$ & $3.2(599434)$ \\
JCOPE-T-1-C & $5.7(225045.64 \%)$ & $2.4(225045)$ & $5.7(227890)$ & $4.6(340037)$ \\
JCOPE-T-2 & $5.5(233850,37 \%)$ & $9.7(233850)$ & $5.7(247538)$ & $26.1(516062)$ \\
JCOPE-T-2-C & $5.9(207099.55 \%)$ & $9.5(207099)$ & $6.2(220190)$ & $19.5(314709)$ \\
JCOPE-T-2-C-E* & $5.9(207967.55 \%)$ & $9.5(207967)$ & - & - \\
JCOPE2 & $5.2(951668.93 \%)$ & $-3.0(951668)$ & $4.3(966469)$ & $0.5(1020253)$ \\
\hline
\end{tabular}

* The result of the simulation with the optimized parameters in the JCOPE-T-2-C case in Table 2.

contribute to the positive perturbation of the atmospheric parameter (Fig. 6A-1).

All four cases of JCOPE-T indicate similar estimates of the total amount of the direct release, 5.5-5.9 PBq, but comparatively broad range of the estimate of the atmospheric deposition, 1.2-9.7 PBq (Table 3). The reason is that the former (latter) parameter is basically determined by the observations near the coast (the observations in both of coastal and open seas) as shown in Fig. 6O-1 and A-1. The smaller estimates of the atmospheric parameter in JCOPE-T- 1 could be related to the unrealistic representation of the open-sea currents and then could be rejected. The variation of ${ }^{137} \mathrm{Cs}$ near the coast mainly driven by the wind forced current (Miyazawa et al., 2012) is not much sensitive to the change of the nudging parameter, which generally affects the open-sea condition (Sect. 2.1), and the detailed shape of the time sequences of the direct release flux. The estimated total amounts of the direct release thus exhibit a convergent result among JCOPET-1 and JCOPE-T-2 models (Table 3).

Figures 7 and 9 depict sequences of the weekly mean concentration of the simulation of JCOPE-T-2-C using the optimized parameters with the smallest expected cost function value (207 099) shown in Table 3 . The cost function value of this simulation (JCOPE-T-2-C-E), 207967 , is quite similar to the expected value (207 099), suggesting the effectiveness of the Green's function approach in the optimization of these parameters. The observed concentration along $141.4^{\circ} \mathrm{E}$ in March 2011 (Fig. 7a and b) is actually reproduced by the inclusion of the atmospheric deposition flux even though the model still underestimates it. The horizontal distribution near FNPP in the last half of April is basically governed by the direct release flux because Fig. $7 b$, c, and d are qualitatively similar to Fig. 5b, c, and d, respectively. The wider scale distribution in open ocean is significantly affected by the atmospheric deposition flux throughout the target period as shown in Fig. 9. The observed anomalous concentration in open ocean during this period is considered to originate from the atmospheric deposition. The optimized parameters
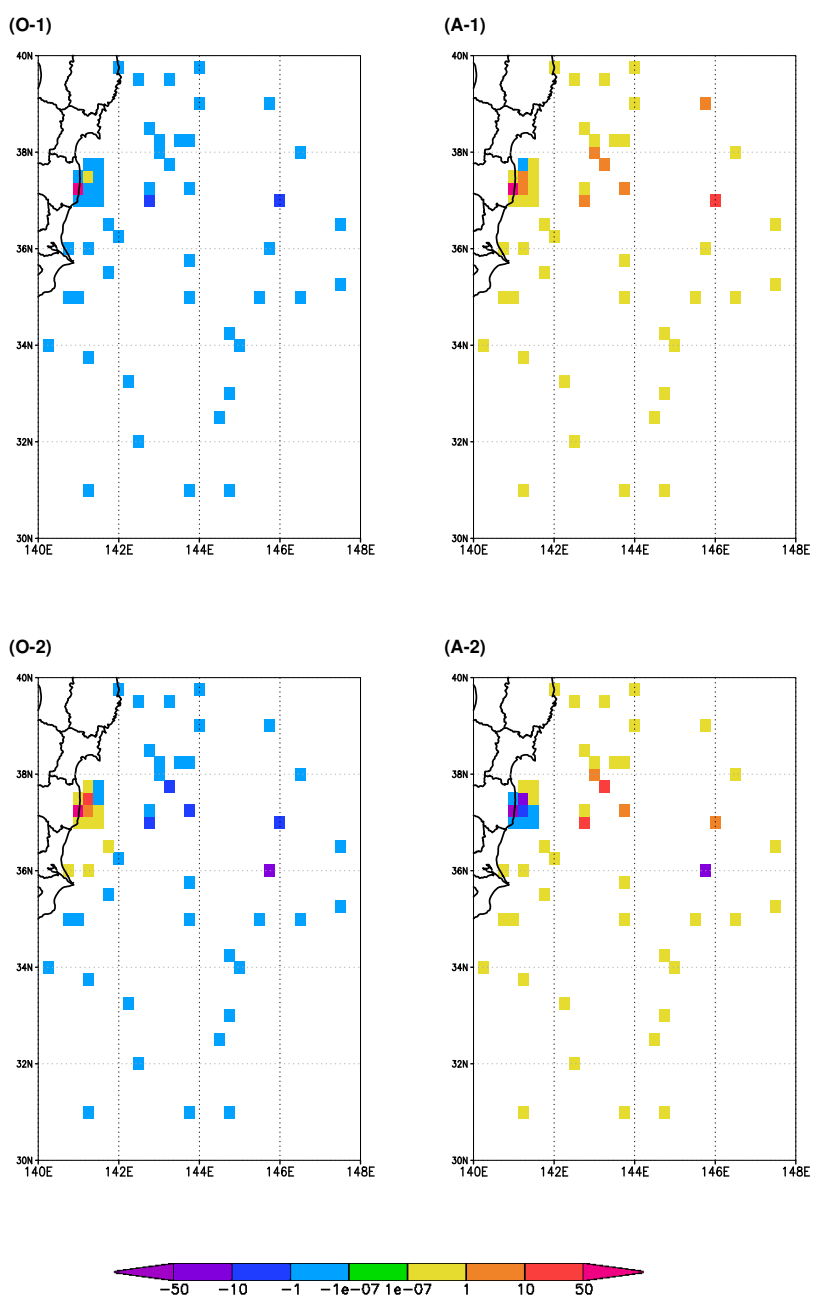

Fig. 6. Contribution rates (in \%; Eq. 9) averaged in $1 / 4^{\circ} \times 1 / 4^{\circ}$ grids. (O-1) The ocean parameter in the JCOPE-T-2-C case. (A-1) The atmospheric parameter in the JCOPE-T-2-case. (O-2) As in $(\mathbf{O}$ 1), except for the JCOPE2 case. (A-2) As in (A-1), except for the JCOPE2 case. 


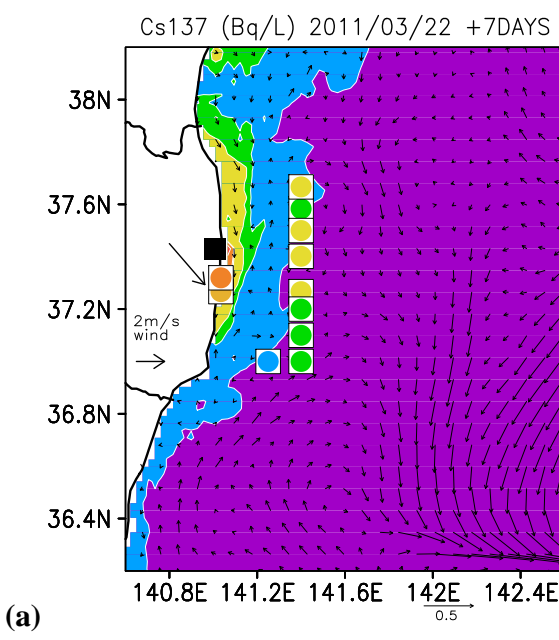

(a)

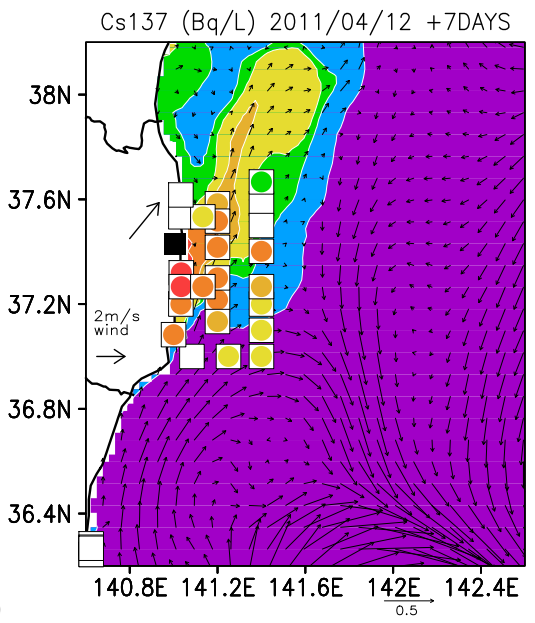

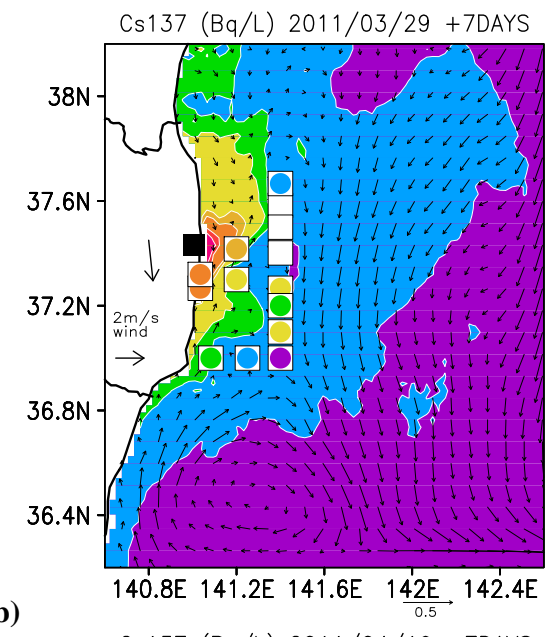

(b)

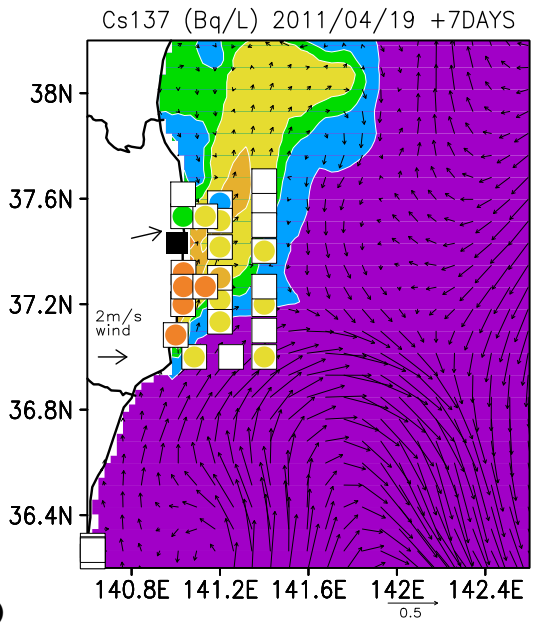

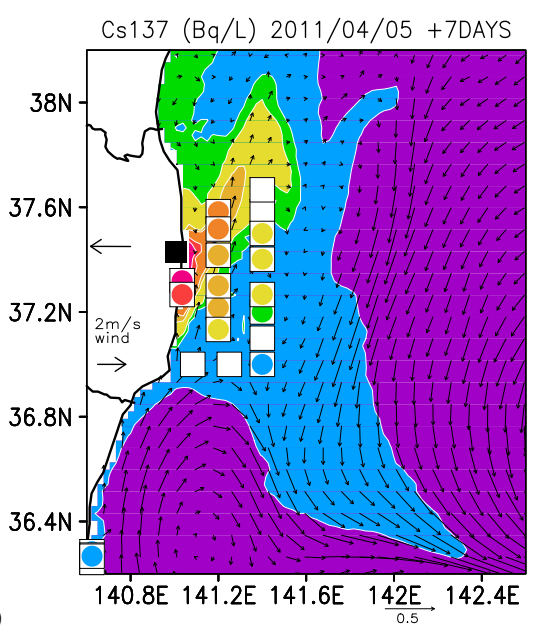

(c)

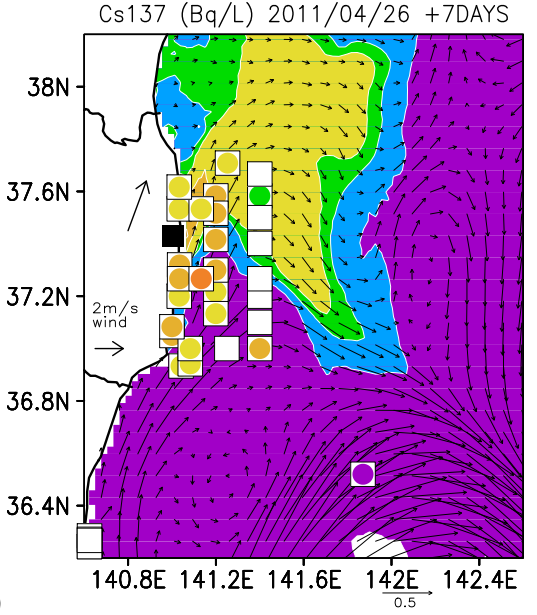

Fig. 7. As in Fig. 5, except for the JCOPE-T-2-C-E case.

allow representation of time sequences of ${ }^{137} \mathrm{Cs}$ variations near FNPP: in front of FNPP, in front of the Fukushima Daini nuclear power plant (10 km south of FNPP), and the Iwasawa Coast (16 km south of FNPP), as observed (Fig. 10), although the peak magnitude of the observation in front of FNPP (Fig. 10a) is not completely reproduced due to the coarse grid $\left(1 / 36^{\circ}\right)$ of the model. The simulation assuming a flat shape of the CRIEPI type flux sequence during the period from 26 March to 6 April 2011 (Fig. 4) reproduces two peaks of the observation in April 2011 as shown in Fig. 10a and results in the smallest cost function value among the all simulations after the parameters optimization (Table 3 ), suggesting that the ${ }^{137} \mathrm{Cs}$ variation in front of FNPP is basically caused not by the direct release flux, but the ocean current variation, as mentioned by Tsumune et al. (2012). Comparison between the measurements and simulation at the TEPCO monitoring points $15 \mathrm{~km}$ off the coast (Fig. 10d, e, and f) indicates that the simulation comparatively reproduces the dispersion northeast of FNPP (Fig. 10d and e), while it underestimates the concentration southeast of FNPP (Fig. 10f). The difference of the skill between northeast and southeast of FNPP does not much affect the estimation of the source parameters because the observations along the coast near FNPP (Fig. 10b and c) dominantly contribute to the estimation (Fig. 6O-1 and A-1).

Normalized error distribution between a first-guess simulation (JCOPE-T-2-C; see Table 2) and the observations generally indicates underestimation of the surface concentration (Fig. 11, BIAS-1). The adjustment of the parameters (JCOPE-T-2-C-E; see Table 3) slightly improves the underestimation (Fig. 11, BIAS-2). Overestimation of the surface concentration near FNPP in a case assuming a larger amount of $14.8 \mathrm{PBq}$ of the direct release (see Table 1 of Masumoto et al., 2012 and Fig. 8a of Miyazawa et al., 2012) partly supports the present estimates of 5.6-5.9 PBq, and underestimation in the region far from FNPP for the case with the larger amount of the direct release (again compare Fig. 11, BIAS2 and Fig. 8a of Miyazawa et al., 2012) suggests the roles 

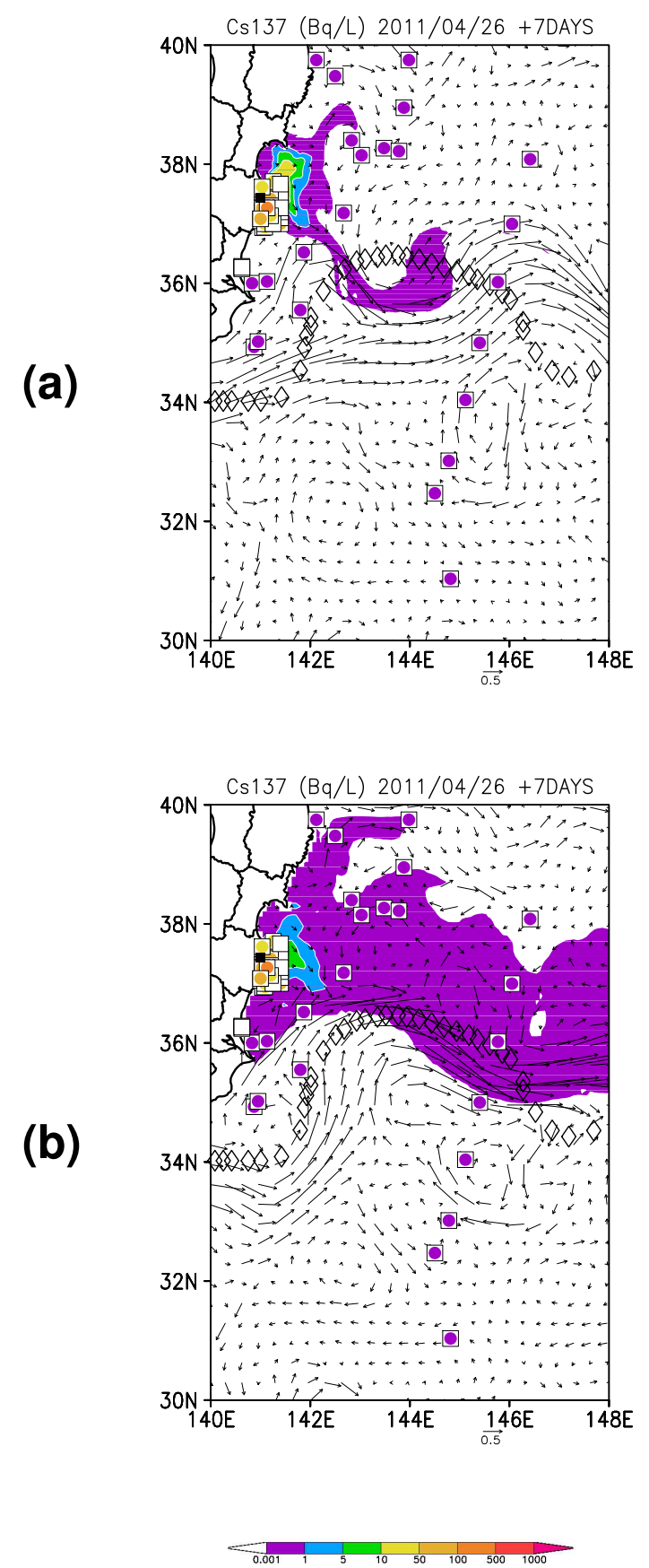

Fig. 8. (a) As in Fig. 5f, except for showing a wider region, and with open diamonds indicating the position of the Kuroshio Extension front provided by Japan Coast Guard. (b) As in (a), except for the JCOPE2 first-guess simulation.

of the atmospheric deposition in the wide-range dispersion. Distribution of root mean square error in the adjusted parameters case (Fig. 11, RMES-2) shows better skill than those of smaller (3.5 PBq; Fig. 11, RMSE-1) and larger (14.8 PBq; Fig. $8 \mathrm{~b}$ of Miyazawa et al., 2012) amounts of the direct release.
The observations obtained at the MEXT monitoring points northeast of FNPP (see open circles in Fig. 12c for locations) indicate three peaks of the surface concentration in the end of March, middle of April, and end of April 2011 (Fig. 12a). The JCOPE-T-2-C-E case generally represents these three peaks. The first peak at the end of March is caused by the atmospheric deposition because the only simulations with the deposition represent the increase of the concentration in this period (see asterisks and open circles in Fig. 12a). The direct release is responsible for the two peaks in April (see open triangles in Fig. 12a). The observation southeast of FNPP also shows the similar three peaks (Fig. 12b). The simulations basically underestimate the concentration in this region. Figure $12 \mathrm{c}$ indicates that the ocean current facilitates the northeastward elongation of the dispersion and prevents the southward transport of ${ }^{137} \mathrm{Cs}$ in April and May 2011. This feature is generally consistent with the observation around the southern part of the Japan coast (Aoyama et al., 2012b). The simulated current slightly different from the real state could considerably affect the dispersion around the monitoring points.

The dominant contributions from atmospheric and oceanic sources could be found in the different periods. The atmospheric deposition started from 12 March 2011 and the peaks of the emission were found only within March 2011 (Fig. 2). The dispersion within March was mainly forced by the atmospheric source. Comparison of the surface concentration on the MEXT monitoring points between the simulations with and without the atmospheric source (compare open circles and squares in Fig. 12a and b) suggests that the concentration in March was caused by the atmospheric deposition around the monitoring points. In contrast, the direct release began on 26 March (Tsumune et al., 2012) and its dominant effect there appeared in April (again see Fig. 12a and b). The horizontal scales of the two processes were also different from each other at least during our target period from 12 March to 6 May 2011. The dispersion triggered by the direct release was basically limited within the shelf region throughout the period (Fig. 8a), but the atmospheric deposition affected the wide region over the western North Pacific (see Fig. 3 in Honda et al., 2012). We thus suggest that comparable contributions from both the atmospheric and oceanic sources did not occur, except for in a narrow region along the coast very near FNPP in the end of March 2011.

The previous studies of the ocean dispersion simulations associated with the Fukushima accident (Kawamura et al., 2011; Tsumune et al., 2012) report $4 \mathrm{PBq}$ for the period from 21 March to 30 April (Kawamura et al., 2011) and $3.5 \pm 0.7 \mathrm{PBq}$ for the period from 26 March to 31 May (Tsumune et al., 2012) of the ${ }^{137} \mathrm{Cs}$ total direct release amount. Their estimates are based on only the observations in front of FNPP (the 5th-6th and south discharge canal waters), while our estimates utilize all available observations, except for the observations in front of FNPP, which may be not well represented by the comparatively coarse grid $\left(1 / 36^{\circ}\right.$ and $\left.1 / 12^{\circ}\right)$ used for our simulation models. However, 


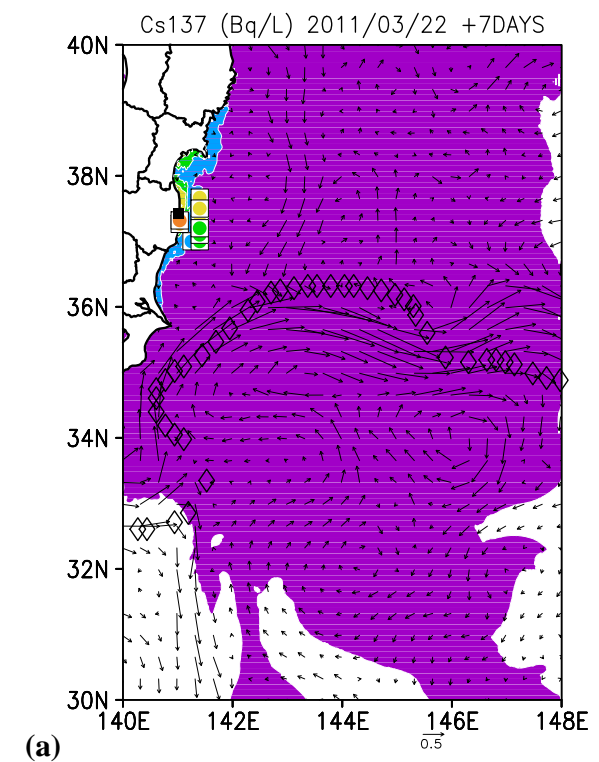

(a)

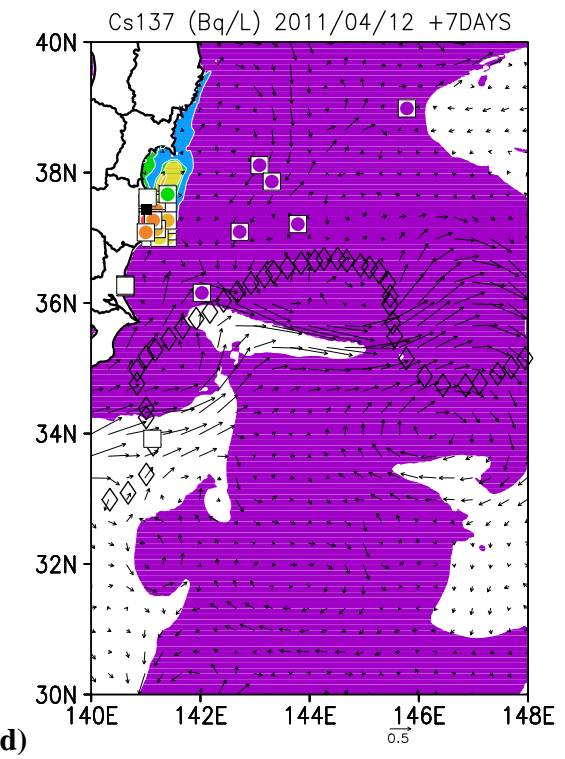

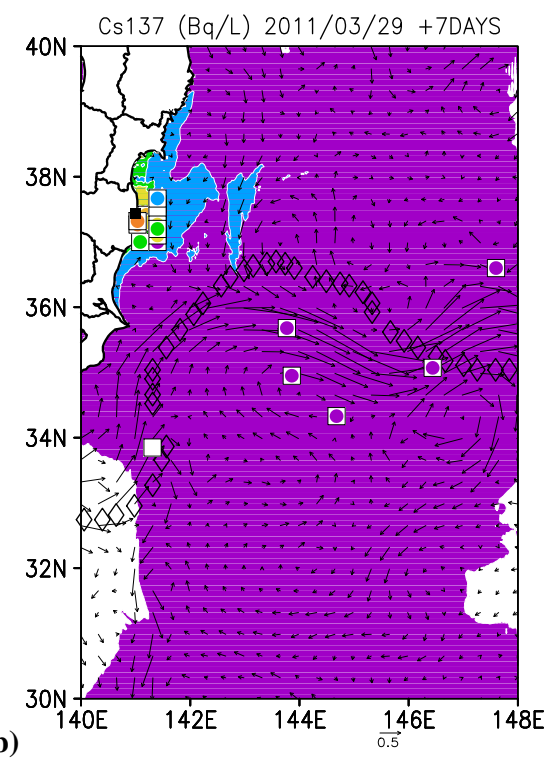

(b)

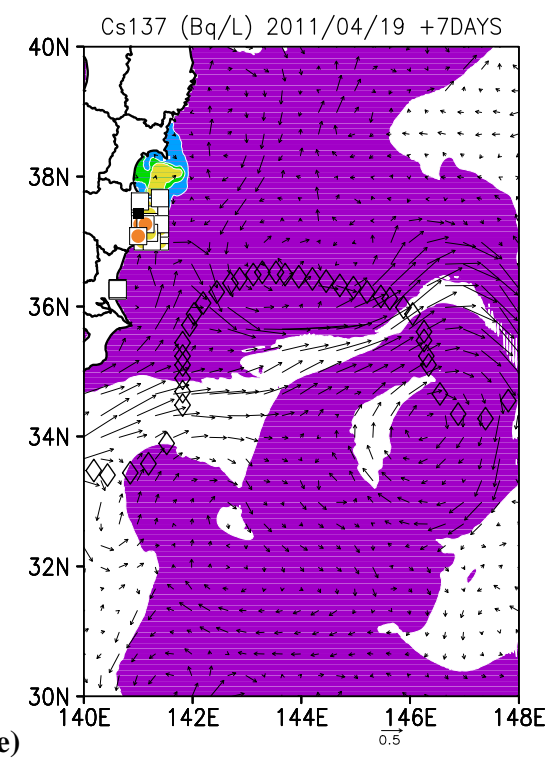

(c)
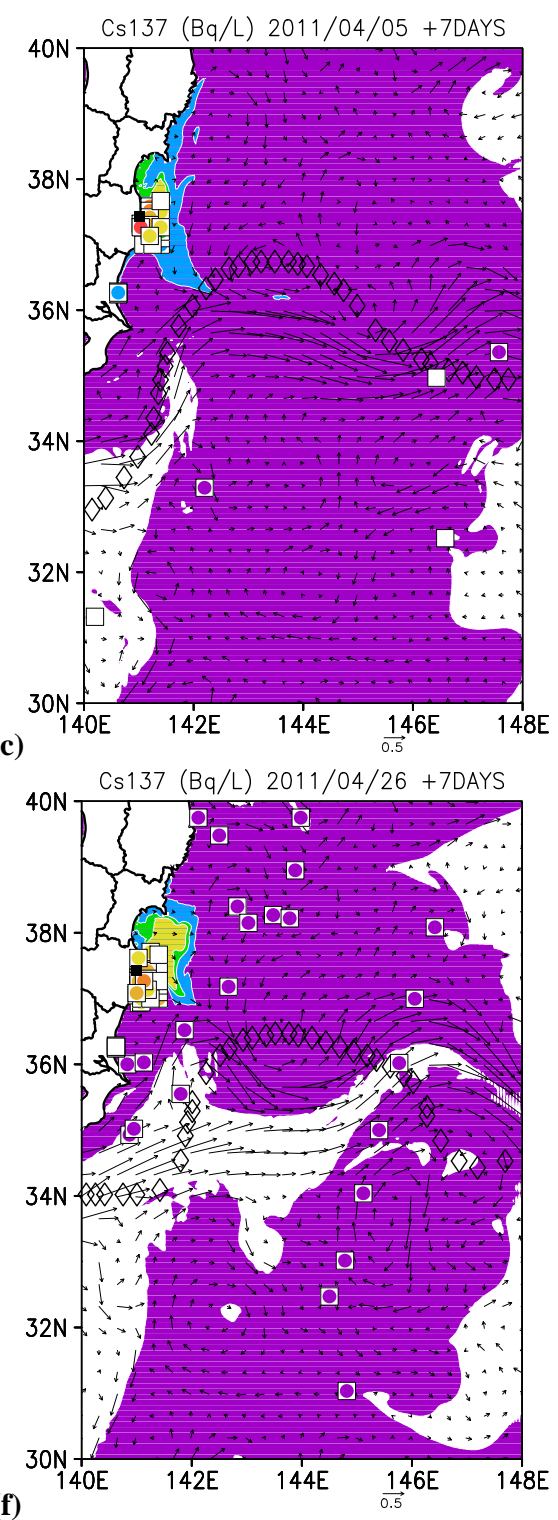

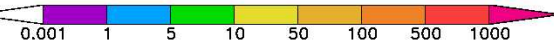

Fig. 9. As in Fig. 7, except for showing a wider region, and with open diamonds indicating the position of the Kuroshio Extension front provided by the Japan Coast Guard.

our larger estimate of the direct release flux, 5.5-5.9 PBq for the period from 21 March to 6 May 2011, succeeds in reproducing the ${ }^{137} \mathrm{Cs}$ variations observed along the coast ,(Fig. 10b and c) although the other model underestimates them (Fig. 11 of Tsumune et al., 2012). The simulation presented by Kawamura et al. (2011) seems to well reproduce them (their Fig. 2), but their simulation represents more enhanced southward dispersion along the coast than our simulations (Masumoto et al., 2012). The difference of estimated total amounts of the direct release among different studies could be attributed to possible differences in the model configurations and acceptable for better understanding of uncer- tainty of the source information. To reduce the uncertainty, additional studies based on the observation data obtained during the extended period (e.g., Aoyama et al., 2012b; Buesseler et al., 2012; Caffrey et al., 2012; Inoue et al., 2012) could be required as well as additional model simulations (e.g., Dietze and Kriest, 2012).

The JCOPE2 simulation is too diffusive and poor in the representation of ${ }^{137} \mathrm{Cs}$ variation near FNPP. However, it could be still utilized for the estimation of the atmospheric deposition in the region over the western North Pacific far from FNPP because it covers the region all over the western North Pacific wider than the JCOPE-T model region. We 
(a)

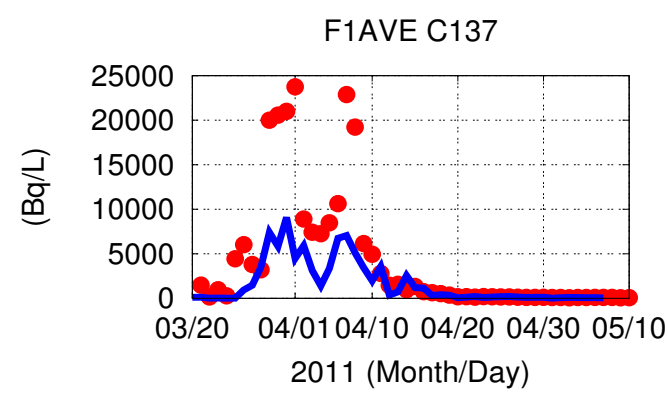

obs $-\operatorname{sim} \longrightarrow$

F2 C137

(b)

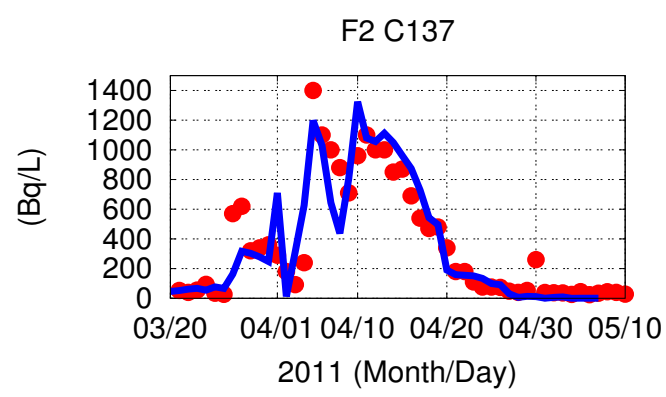

obs $\bullet \operatorname{sim}$

IW C137

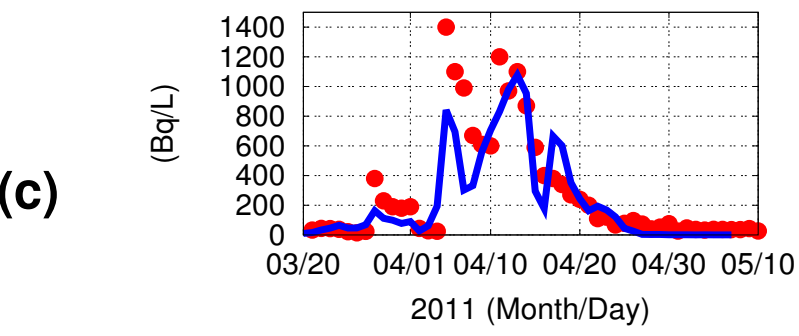

obs $\bullet \operatorname{sim} \longrightarrow$ (d)

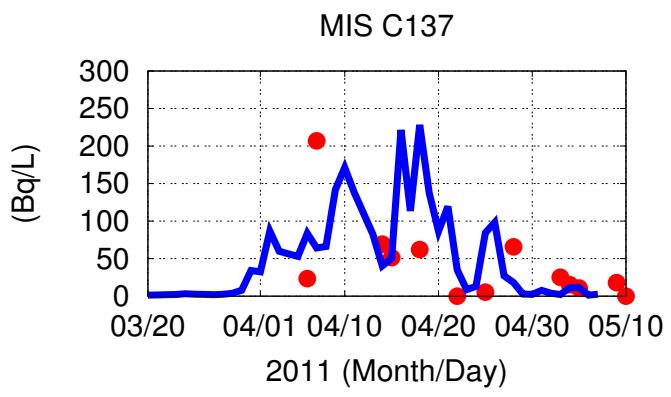

obs • sim

F115 C137

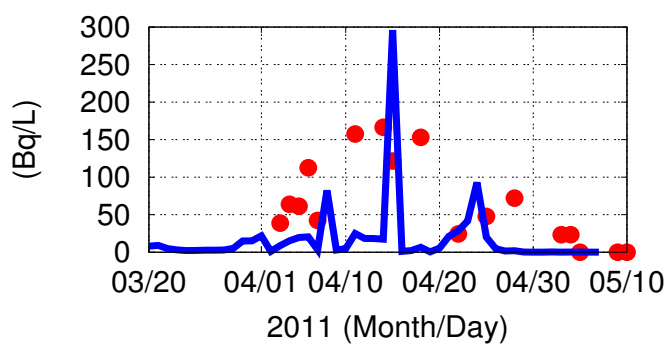

obs $\bullet \operatorname{sim} \longrightarrow$

(f)

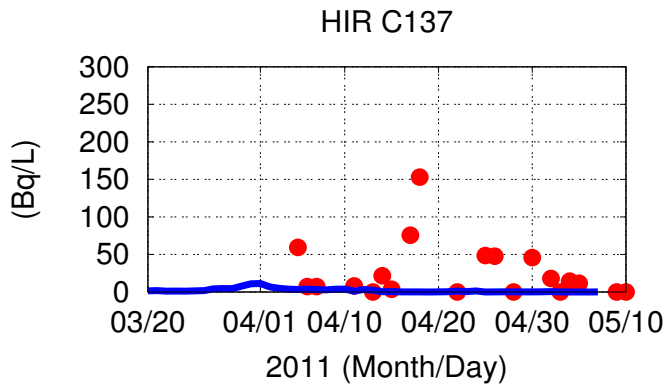

obs

Fig. 10. Time sequences (curves) of ${ }^{137} \mathrm{Cs}$ at $1 \mathrm{~m}$ depth on the points along the Fukushima coast simulated by the JCOPE-T-2-C-E case. Closed circles denote the observation at the corresponding points (see Fig. 12c for locations). (a) In front of FNPP. Closed circles denote the average of the measurements at two positions of the 5th-6th and south discharge canal waters. (b) In front of Fukushima Daini nuclear power plant (10 km south of FNPP). (c) The Iwasawa Coast (16 km south of FNPP). (d) $15 \mathrm{~km}$ off Minamisoma. (e) $15 \mathrm{~km}$ off FNPP. (f) $15 \mathrm{~km}$ off Hirono.

estimate the total amount of only the atmospheric deposition, 5.5 PBq (the JCOPE2-A case; Table 4), using the outputs from the JCOPE2 simulations and the observation data obtained in the western North Pacific region excluding the region near FNPP, $29-45^{\circ} \mathrm{N}$ and $130-150^{\circ} \mathrm{E}$ (see Fig. 3). This value also provides a possible estimate of the total amount of the atmospheric deposition over the western North Pacific. In this case it is impossible to estimate the total amount of the direct release because of no sensitivity for the ${ }^{137} \mathrm{Cs}$ concentration in the region far from FNPP.
Table 4. As in Table 3, except for the parameter optimization of the JCOPE2-A case. Percent number denotes the reduced ratio of the cost function as compared to the first-guess value of 5092 .

\begin{tabular}{ll}
\hline & Atmosphere-Single \\
\hline JCOPE2-A & $5.5(3579.70 \%)$ \\
\hline
\end{tabular}



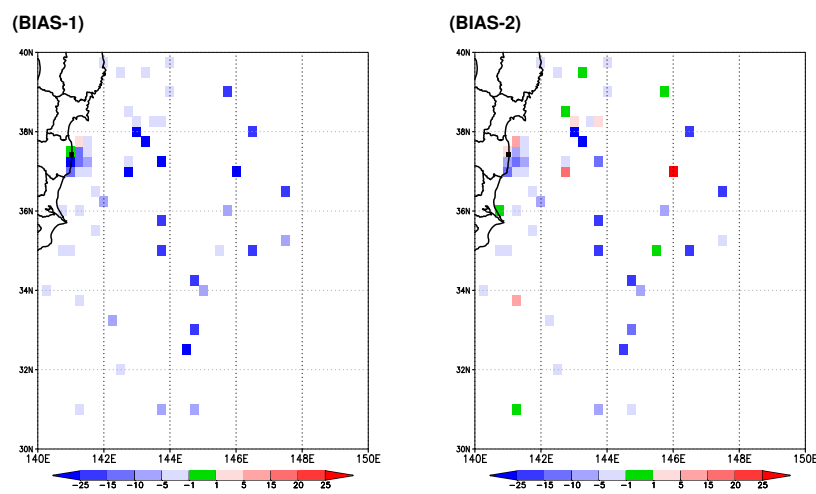

(RMSE-1)
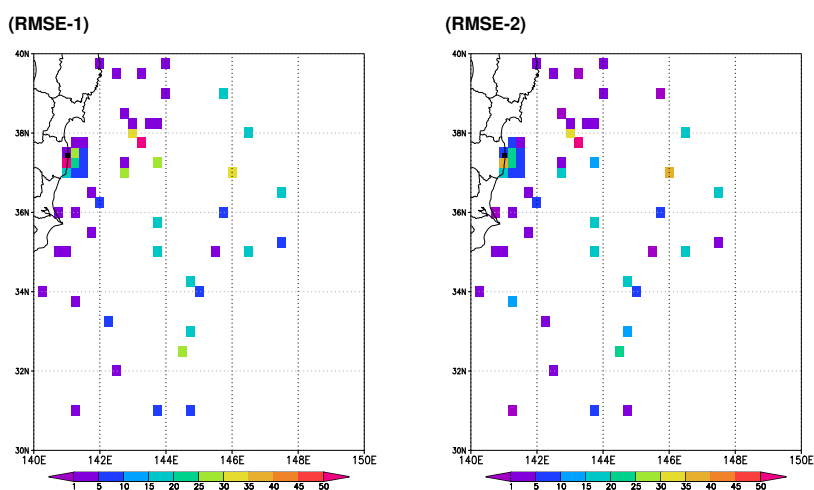

Fig. 11. Gridded distributions of mean error (BIAS) and root mean square error (RMSE) between the simulated and observed ${ }^{137} \mathrm{Cs}$ surface concentration for the period from 21 March to 6 May 2011, normalized by the measurement errors (see Table 1). Grid resolution is $1 / 4$. The position of FNPP is denoted by a closed square. Left (right) panels denote the JCOPE-T-2-C (JCOPE-T-2-C-E) case.

Our estimates of the total amount of the atmospheric deposition over the western North Pacific $\left(12-62^{\circ} \mathrm{N}, 108-180^{\circ} \mathrm{E}\right)$ have an uncertainty range, 5.5-9.7 PBq (Tables 3 and 4), which is comparable to the reported estimates: $5 \mathrm{PBq}$ for the period from 12 March to 30 April 2011 in the similar region, $30.5-48^{\circ} \mathrm{N}, 127-154.5^{\circ} \mathrm{E}$ (Kawamura et al., 2011), and $12-15 \mathrm{PBq}$ for the period from March to May 2011 in the North Pacific (Aoyama et al., 2013). The total amount of the atmospheric deposition should be examined more in detail in the future.

\section{Summary}

By using the ocean-atmosphere simulation models and field observation data, we evaluate the parameters associated with the total caesium-137 $\left({ }^{137} \mathrm{Cs}\right)$ amounts of the direct release and atmospheric deposition caused by the accident of Fukushima Daiichi nuclear power plant (FNPP) that occurred in March 2011. The Green's function approach (Menemenlis et al., 2005) is utilized for the estimation of two simple parameters determining the absolute values of the total

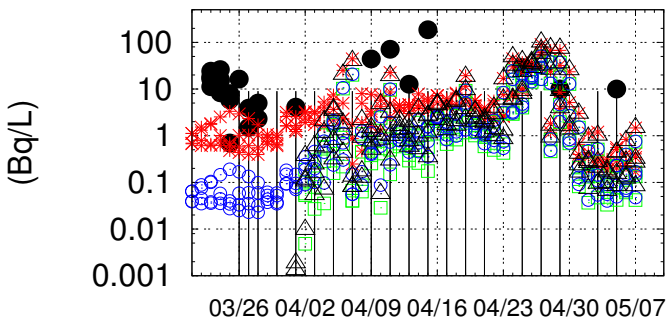

(Month/Day) 2011

(a)
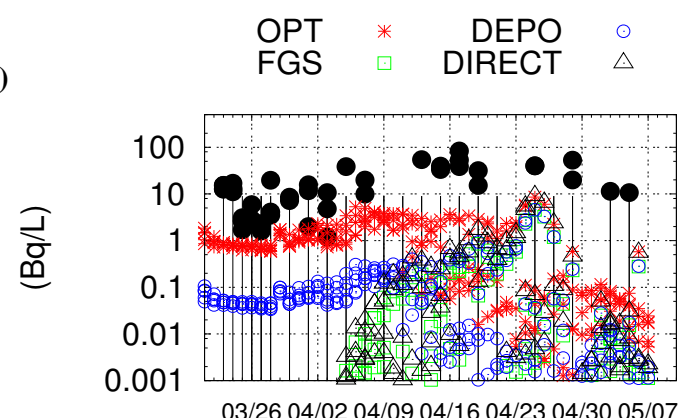

(Month/Day) 2011

(b)
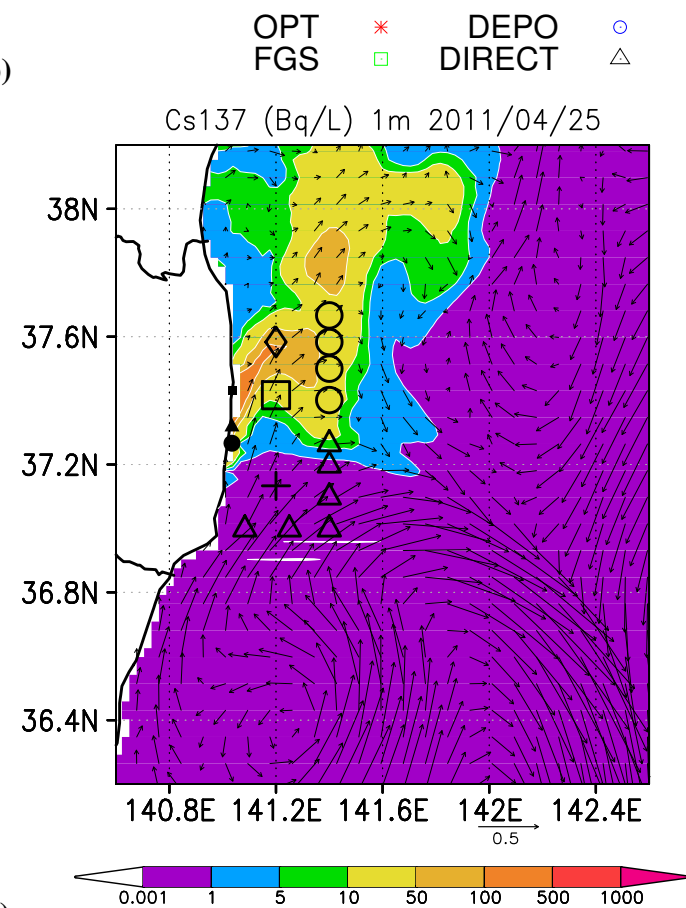

(c)

Fig. 12. (a) Time sequences of ${ }^{137} \mathrm{Cs}$ at $1 \mathrm{~m}$ depth on the points northeast of FNPP, denoted by open circles shown in (c). Closed circles: MEXT observation (see Table 1) Asterisks: JCOPE-T-2-C-E. Open squares: JCOPE-T-2-C. Open circles: the sensitivity experiment for the atmospheric deposition. Open triangles: the sensitivity experiment for the direct release. Vertical bars: measurements reporting ${ }^{137} \mathrm{Cs}$ activities below the detection limit, $10 \mathrm{BqL}^{-1}$. (b) As in (a), except for the points southeast of FNPP, indicated by open triangles shown in (c). (c) Daily mean ${ }^{137} \mathrm{Cs}$ concentration (in $\mathrm{BqL}^{-1}$ ) on 25 April 2011 at $1 \mathrm{~m}$ depth (shaded) simulated by the JCOPE-T-2-C-E case. Vectors indicate the daily mean current at $1 \mathrm{~m}$ depth. The position of FNPP is denoted by a closed square. The TEPCO monitoring points are indicated by a closed triangle (Fukushima Daini nuclear power plant), a closed circle (the Iwasawa Coast), an open diamond (15 km off Minamisoma), an open square (15 km off FNPP), and a plus sign $(15 \mathrm{~km}$ off Hirono). The MEXT monitoring points are indicated by open circles and triangles. 
emission amounts for the period from 12 March to 6 May 2011. The first-guess simulations are conducted by two types of ocean models: a coarser grid $\left(1 / 12^{\circ}\right)$ - basin-scale, and a finer grid $\left(1 / 36^{\circ}\right)$ - downscaled models. The downscaled model reasonably represents the contrast of the dispersions near FNPP dominantly governed by the direct release, and in open ocean basically determined by the atmospheric dispersion, resulting in the plausible estimate of the total amounts of both the direct release and atmospheric dispersion. The basin-scale model could be used for the estimation of the total amount of the atmospheric deposition widely spread over the western North Pacific.

\section{Supplementary material related to this article is

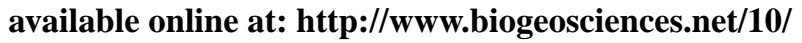 2349/2013/bg-10-2349-2013-supplement.zip.}

Acknowledgements. This work is part of the Japan Coastal Ocean Predictability Experiment (JCOPE) promoted by the Japan Agency for Marine-Earth Science and Technology (JAMSTEC). The authors wish to thank the numerical modeling subgroup of the Oceanographic Society of Japan, led by Motoyoshi Ikeda, for many useful suggestions. The authors would also like to thank the fruitful discussions with Daisuke Tsumune, Michio Aoyama, and Takuya Kobayashi. We are grateful for comments and suggestions from two anonymous reviewers and the handling editor Pavel Povinec.

Edited by: P. Povinec

\section{References}

Aoyama, M., Igarashi, Y., and Hirose, K.: Learning from the monthly measurement of the fallout during 660 months $-90 \mathrm{Sr}$, ${ }^{137} \mathrm{Cs}$, and Pu fallouts from April 1957 to March 2012, Sci. J. KAGAKU, 82, 442-457, 2012a. (in Japanese).

Aoyama, M., Tsumune, D., Uematsu, M., Kondo, F., and Hamajima, Y.: Temporal variation of ${ }^{134} \mathrm{Cs}$ and ${ }^{137} \mathrm{Cs}$ activities in surface water at stations along the coastline near the Fukushima Daiichi Nuclear Power Plant, accident site, Japan, Geochemical J., 46, 321-325, 2012b.

Aoyama, M., Tsumune, D., and Hamajima, Y.: Distribution of ${ }^{137} \mathrm{Cs}$ and ${ }^{134} \mathrm{Cs}$ in the North Pacific Ocean: impacts of the TEPCO Fukushima-daiichi NPP accident, J. Radioanal. Nucl. Ch., 296, Page 535-539, doi:10.1007/s10967-012-2033-2, 2013.

Bailly du Bois, P., Laguionie, P., Boust, D., Korsakissok, I., Didier, D., and Fievet, B.: Estimation of marine source-term following Fukushima Dai-ichi accident, J. Environ. Radioact., 114, 2-9, 2012.

Buesseler, K., Aoyama, M., and Fukasawa, M.: Impacts of the Fukushima nuclear power plants on marine radioactivity, Environ. Sci. Tech., 45, 9931-9935, doi:10.1021/es202816c, 2011.

Buesseler, K. O., Jayne, S. R., Fisher, N. S., Rypina, I. I., Baumann, H., Baumann, Z., Breier, C. F., Douglass, E. M., George, J., Macdonald, A. M., Miyamoto, H., Nishikawa, J., Pike, S. M., and
Yoshida, S. : Fukushima-derived radionuclides in the ocean and biota off Japan, P. Natl. Acad. Sci., 109, 5984-5988, 2012.

Caffrey, J. A., Higlay, K. A., Farsoni, A. T., Smith, S., and Menn, S. : Development and deployment of an underway radioactive cesium monitor off the Japanese coast near Fukushima Dai-ichi, J. Environ. Radioact., 111, 120-125, 2012.

Chino, M., Nakayama, H., Nagai, H., Terada, H., Katata, G., and Yamazawa, H.: Preliminary estimation of release amounts of 131I and ${ }^{137}$ Cs accidentally discharged from the Fukushima daiichi nuclear power plant into the atmosphere, J. Nucl. Sci. Technol., 48, 1129-1134, 2011.

Conkright, M. E., Antonov, J. I., Baranova, O., Boyer, T. P., Garcia, H. E., Gelfeld, R., Johnson, D., Locarnini, R. A., Murphy, P. P., O’Brien, T. D., Smolyar, I., and Stephens, C.: World Ocean Database 2001, Volume 1: Introduction, edited by: Levitus, S., NOAA Atlas NESDIS 42, US Government Printing Office, Washington DC, 167 pp., 2002.

Dietze, H. and Kriest, I.: ${ }^{137}$ Cs off Fukushima Dai-ichi, Japan model based estimates of dilution and fate, Ocean Sci., 8, 319332, doi:10.5194/os-8-319-2012, 2012.

Guo, X., Varlamov, S. M., and Miyazawa, Y.: Coastal ocean modeling by nesting method, B. Coast. Oceanogr., 47, 113-123, 2010 (in Japanese with English abstract and figure captions).

Honda, M., Aono, T., Aoyama, M., Hamajima, Y., Kawakami, H., Kitamura, M., Masumoto, Y., Miyazawa, Y., Takigawa, M., and Saino, T.: Dispersion of artificial caesium-134 and -137 in the western North Pacific one month after the Fukushima accident, Geochemical J., 46, e1-e9, 2012.

Inoue, M., Kofuji, H., Nagao, S., Yamamoto, M., Hamajima, Y., Yoshida, K., Fujimoto, K., Takada, T., and Isoda, Y.: Lateral variation of ${ }^{134} \mathrm{Cs}$ and ${ }^{137} \mathrm{Cs}$ concentrations in surface seawater in and around the Japan Sea after the Fukushima Daiichi Nuclear Power Plant accident, J. Environ. Radioact., 109, 45-51, 2012.

Kagimoto, T., Miyazawa, Y., Guo, X., and Kawajiri, H.: High resolution Kuroshio forecast system - Description and its applications-, in High Resolution Numerical Modeling of the Atmosphere and Ocean, edited by: Ohfuchi, W. and Hamilton, K., Springer, New York, 209-234, 2008.

Kalnay, E., Kanamitsu, M., Kistler, R., Collins, W., Deaven, D., Gandin, L., Iredell, M., Saha, S., White, G., Woollen, J., Zhu, Y., Leetmaa, A., Reynolds, R., Chelliah, M., Ebisuzaki, W., Higgins, W., Janowiak, J., Mo, K., C., Ropelewski, C., Wang J., Jenne, R., and Joseph, D.: The NCEP/NCAR 40-Year Reanalysis Project, B. Am. Meteor. Soc., 77, 437-471, 1996.

Kawamura, H., Kobayashi, T., Furuno, A., In, T., Ishikawa, Y., Nakayama, T., Shima, S., and Awaji, T.: Preliminary numerical experiments on oceanic dispersion of ${ }^{131} \mathrm{I}$ and ${ }^{137} \mathrm{Cs}$ discharged into the ocean because of the Fukushima daiichi nuclear power plant disaster, J. Nucl. Sci. Tech., 48, 1349-1356, 2011.

Li, Y., Gao, Z., Lenschow, D. H., and Chen, F.: An improved approach for parameterizing surface-layer turbulent transfer coefficients in numerical models, Bound.-Lay. Meteorol., 137, 153165, 2010.

Maryon, R. H., Saltbones, J., Ryall, D. B., Bartnicki, J., Jakobsen, H. A., and Berge, E.: An intercomparison of three long range dispersion models developed for the UK meteorological office, DNMI and EMEP, UK Met Office Turbulence and Diffusion, Note 234, ISBN:82-7144-026-08, 44 pp., 1996. 
Masumoto, Y., Miyazawa, Y., Tsumune, D., Kobayashi, T., Estournel, C., Marsaleix, P., Lanerolle, L., Mehra, A., and Garraffo, Z. D.: Oceanic dispersion simulation of Cesium 137 from Fukushima Daiichi Nuclear Power Plant, Elements, 8, 207-212, 2012.

Matsumoto, K., Takanezawa, T., and Ooe, M.: Ocean tide models developed by assimilating TOPEX/POSEIDON altimeter data into hydrodynamical model: a global model and a regional model around Japan, J. Oceanogr., 56, 567-581, 2000.

Menemenlis, D., Fukumori, I., and Lee, L.: Using Green's functions to calibrate an ocean general circulation model, Mon. Weather Rev. 133, 1224-1240, 2005.

Mellor, G. and Blumberg, A. F.: Wave breaking and ocean surface layer thermal response, J. Phys. Oceanogr., 34, 693-698, 2004.

Mellor, G., Hakkinen, S., Ezer, T., and Patchen, R.: A generalization of a sigma coordinate ocean model and an intercomparison of model vertical grids, in: Ocean Forecasting: Conceptual Basis and Applications, edited by: Pinardi, N. and Woods, J. D., Springer, New York, 55-72, 2002.

Ministry of Education, Culture, Sports, Science and Technology (MEXT): Monitoring gginformation of environmental radioactivity level, http://radioactivity.mext.go.jp/en/, 2011.

Miyazawa, Y., Zhang, R., Guo, X., Tamura, H., Ambe, D., Lee, J.S., Okuno, A., Yoshinari, H., Setou, T., and Komatsu, K.: Water mass variability in the western North Pacific detected in a 15year eddy resolving ocean reanalysis, J. Oceanogr. 65, 737-756, 2009.

Miyazawa, Y., Masumoto, Y., Varlamov, S. M., and Miyama, T.: Transport simulation of the radionuclide from the shelf to open ocean around Fukushima, Cont. Shelf Res., 50-51, 16-29, 2012.

Morino, Y., Ohara, T., and Nishizawa, M.: Atmospheric behavior, deposition, and budget of radioactive materials from the Fukushima Daiichi nuclear power plant in March 2011, Geophys. Res. Lett., 38, L00G11, doi:10.1029/2011GL048689, 2011.

Nuclear Emergency Response Headquarters (NERH), Government of Japan: Report of the Japanese Government to the IAEA Ministerial Conference in Nuclear Safety - The accident at TEPCO's Fukushima Nuclear Power Stations, http://www.iaea. org/newscenter/focus/fukushima/japan-report/, 7 June 2011.
Oura, Y. and Ebihara, M.: Radioactivity concentrations of ${ }^{131} \mathrm{I}$, ${ }^{134} \mathrm{Cs}$ and ${ }^{137} \mathrm{Cs}$ in river water in the Greater Tokyo Metropolitan area after the Fukushima Daiichi Nuclear Power Plant Accident, Geochemical J., 46, 303-309, 2012.

Saito, K., Aranam, K., Hara, T., Segawa, T., Narita, M., and Honda, Y.: Nonhydrostatic atmospheric models and operational development at JMA, J. Meteor. Soc. Jpn. 85B, 271-304, 2007.

Smagorinsky, J.: General circulation experiments with the primitive equations, I. The basic experiment, Mon. Weather Rev., 91, 99164, 1963.

Stohl, A., Seibert, P., Wotawa, G., Arnold, D., Burkhart, J. F., Eckhardt, S., Tapia, C., Vargas, A., and Yasunari, T. J.: Xenon133 and caesium-137 releases into the atmosphere from the Fukushima Dai-ichi nuclear power plant: determination of the source term, atmospheric dispersion, and deposition, Atmos. Chem. Phys., 12, 2313-2343, doi:10.5194/acp-12-2313-2012, 2012.

Takemura, T., Nakamura, H., Takigawa, M., Kondo H., Satonuma, T., Miyasaka, T., and Nakajima, T.: A numerical simulation of global transport of atmospheric particles emitted from the Fukushima Daiichi Nuclear Power Plant, SOLA, 7, 101-104, doi:10.2151/sola.2011-026, 2011.

Tokyo Electric Power Corporation (TEPCO): Detection of radioactive materials from the seawater around the discharge canal of Fukushima Daiichi Nuclear Power Station, Press Release, http://www.tepco.co.jp/en/press/corp-com/ release/11032201-e.html, 22 March 2011.

Tsumune, D., Tsubono, T., Aoyama, M., and Hirose, K.: Distribution of oceanic ${ }^{137} \mathrm{Cs}$ from the Fukushima Dai-ichi Nuclear Power Plant simulated numerically by a regional ocean model, J. Environm. Radioact., 111, 100-108, 2012. 